\title{
خصائص الإسلام ودورها في تحقيق الأمن الثقافي
}

اعداد: د.عثمان عبدالرحمن عبدالله عثماناها)

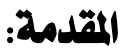

الحمد الله رب العالمين، والصلاة والسلام على اشرف خلق الله

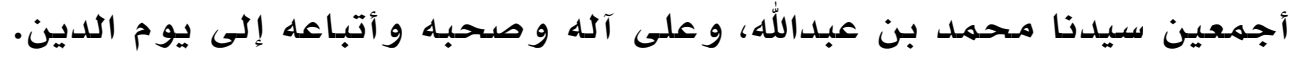

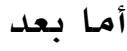

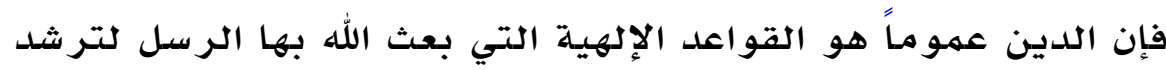
الناس إلى الحق في الإعتقاد و إلى الخير في السلو كك و الهعاملـة، بحيث أنها

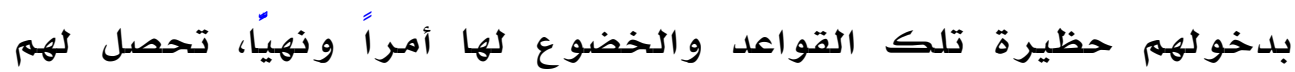

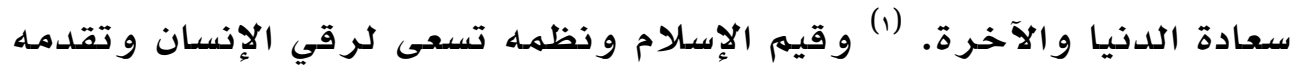

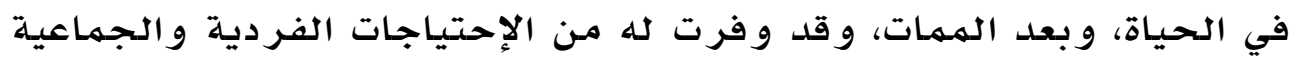

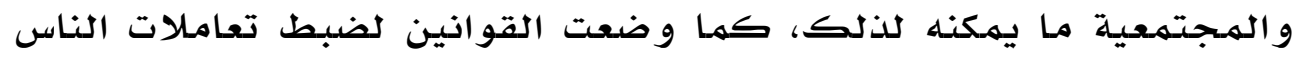

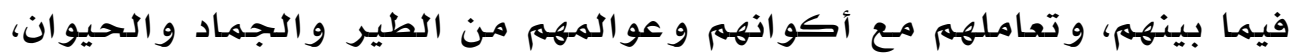
فكلهم خلقوا بقدر.

هذا و قد تضمنت خصائص الإسلام من خلال وظائفها و أدوارها مـا

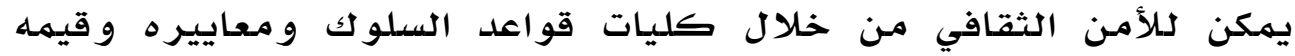

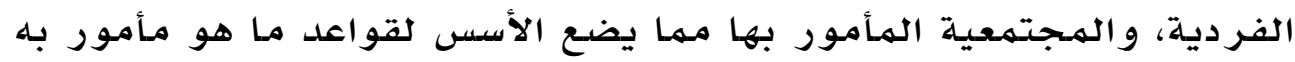

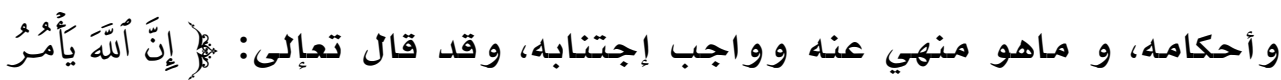

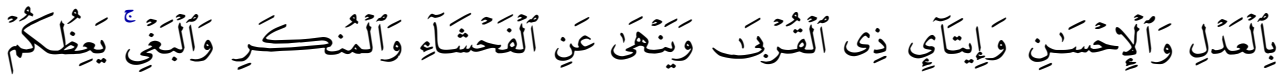

(*) اسـتاذ الــدعوة والثقافـة الإسـلامية المســاعد بكليـة الــدعوة الإســلامية، جامعسة أم درمان الإسلامية.

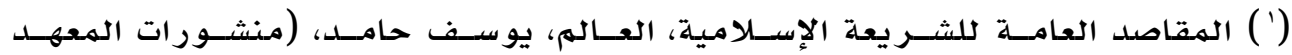
101

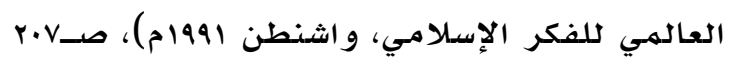




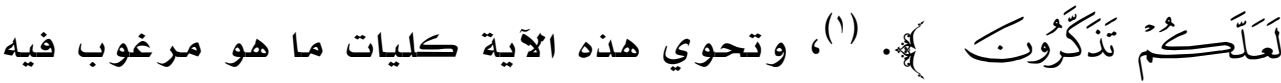

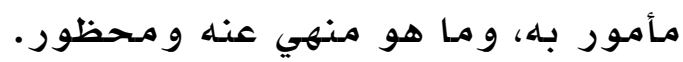

و هذا الفهم جعل الهؤمسن يتسـاءل عن سر خلقه وتهتعهـ بكل هذه

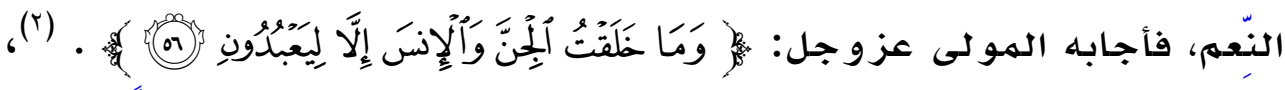
فالعبادة هي سر دوام النعهمة في الدنيا واكتهمالها في الآخرة، إذاً العبـادة مستحقة مقابل مـا تفضل بـه الهـولى مـ النّعهم، ولتكون العبـادة على فهم و تدبرّ، أمـر الله العباد بالتفكر و النظر إلى قيهم هذا الدين و نظهـه.

وهذا البحث يتتناول خصائص الإسلام، كها يتناول دورها في تحقيق الأمن الثقافي.

المستخخله:

اسم البـحث : خصـائص الإسـلام ودورها في تحقيق الأمن الثقافي

للباحث : د. عثمان عبدالر حهن عبدالله عثهـان. (r) مشكلة البحث: أهم التساؤ لات:

ا-مـا حدود الخصائص في الفكر الإسـلاهي؟

ץ-هل توجد خصائص مهاثلة في الفكر الغربي؟

س-هل يهكن وضع مقارنة بين حدود خصائص الإسلام ما بين الفكر

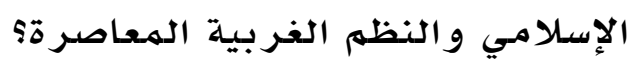

أهمية البحث:

ا-يهتم البحث بإظهار جانب من جوانب حكمة تحقيق الأمن الثقافي في

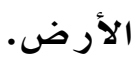

ץ-يبرز وظيفة المسلهم تجاه نفسه ورجتهعه حتى تعود النظهم الإسلامية

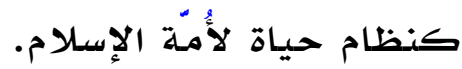

$$
\text { سورة النحل الآية: .9 سورة الذاريات الآية: }
$$

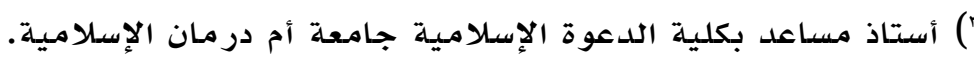


ץ-سبب إختيار هذا العنوان: دفعتني رغبتي في الوقوف على ما كتبـه أهل العلم عن الأمن الثقافي.

\section{منهج البحث:}

بغية تحقيق الأهداف اعتمددت الهنهج الوصفي التحليلي؛ لوضـ الأفكار في سياقها السليهم، وتحليلها وربطها ببعضها البعض، لبيان التشاكل و التمايز بين موقف الإسلام و الهسلهـين مـن الأمـن الثقافي، وموقف الأبحاث النقدية و الدينية الححديثة في الغرب.

أهم النتائج:

ان سعي الإسـلام بتشر يعاته و أحكامـه و مُثله وخصائصسه إلى تحقيق الأمـن والأمـان في الأرض، و لا يتناقض هذا مـع حثثه على الزهد في الدنيا و الرغبـة عنها، فالأمن الثقافي لا يتم الا بتطبيق أحكام الشرع وتطبيقاته تسبقه النيـة، ووهذه النيـة هي بساط الهؤمسن إلى الآخرة، فنشر دين الإسـلام في الأرض و العمل بهتضـاه يفضي إلى تحقيق الأمـن بكل أذواعه و الفلاح في الآخرة، فينتفي التضساد بين الأمـرين.

ا- ان خصدائص الإسلام هي الأسس التي يبنسى عليها الدين ويتهيز بها

$$
\text { عن غيره. }
$$

$$
\text { r- أسس و مصسادر التشـريع في الكتاب و السنـة. }
$$

r- وأن أهم مـاتميزت به شريعة الإسـلام أنها سعت لتحقيق مصساتح العباد في كل زمان عبر تشريعات و أنها مـن قبل مشرِّرع حكيهم. ع- التالازم بين الإيهان والأمن في قول رسول الله صلى الله عليـ و سله: (اللههم أهله علينا بالأمن والإيهمان...). ه- كهما أن تحقيق الأمن الثقافي يشبع حاجات الإنسان الهعنوية و الثقافيـة.

ج- في الهـال الثقافي نجد أن الأمن مهم لحماية الأمهة مـن التيارات الثقافية لا سيما الهدامـة منهـا.

\section{أهم التوهيات:}

نحمد الله عزوجل على مـا بلى للناس من صحوة بين الشباب 17. 
الهسلهم ورفضه للتشريعات غير الإسدلامية التي تحكم بها غالب الشعوب المسلمهة، وذوصي هؤلاء الشباب بالأخذ بأسباب التمكين حتى يتم لهم

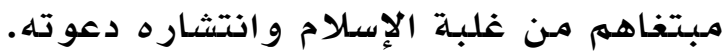

ا- لابد مـن رعايـة الأمن الثقافي بـاستخدام جهيع الوسائط الهـهكنة بها

$$
\text { فيها المستتحدثة. }
$$

ץ- و وكذلك الإهتهمام بخصائص الإسلام، و الكتابـة حول الأمـن و أهميتـه

$$
\text { و أنه مـربوط بالأمن الغذائي و الإجتهماعي. }
$$

ب- كما يوصي الباحث بالكتابة عن كيفية حماية الثقافة الإسلامية

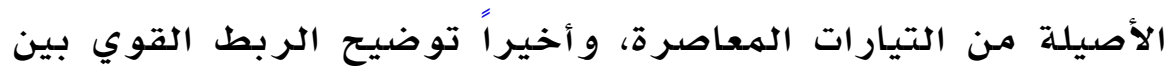
الأمـن الغذائي و الثقافي، و السيـاسي، و الجغر افي، و غير ها. ع- تحقيق الأمن الثقافي يحافظ على الهويـة الثقافية كلأمسة الإسـلاميـة. ه- ان خصائص الإسلام تحافظ على الهاضي وتثري الحاضر

$$
\text { و المسـتقبل. }
$$

لذا فإن خصائص الإسلام ما هي إلا تحقيق للأمن الثقافي الذي الذي يشكل النسق الإجتهاعي، وهو نسقاً فر عيا متهميزأ و مستقلا، لكنـه يتفاعل مـع بقية الأنساق الفرعية الأخرى ويتطور معها وبها، ويقوم الأمـن الثقافي بتكوين جملة الطرائق والهعايير التي تحكهم رؤية الإنسان للواقع؛ لذلك فإن الثقافة هي مـجموع القيهم والقواعد و الأعر اف و التقاليد والخطط التي تبدع وتنظم الدلالات العقلية و الروحية و الجسدية. 


\section{Abstract}

Praise be to God, we praise Him, seek assistance from Him, seek guidance from Him, and seek refuge in Him from the evils of ourselves, and from our bad deeds. Whoever God guides is not misled by Him, and whoever misleads has no guide, and I bear witness that there is no god but God and He has no partner and I bear witness that Muhammad is His servant and His Messenger.

Cultural security forms within the general social order, a distinct and independent sub-system, but it interacts with and develops with the rest of the other sub-systems with and with it, and cultural security forms the set of methods and standards that govern the human vision of reality. Therefore, culture is the sum of the values, rules, norms, traditions, and plans that create and organize mental, spiritual and physical connotations, and work to maintain the balance, stability and unity of the social order, and unify the sub-systems of the social system with similar values, thus creating a single social fabric capable of producing itself.

Therefore, cultural security is in reality nothing but society itself and it has become a manifestation of consciousness or awareness, and this awareness is at the same time self-awareness. The research aims to demonstrate the basis of cultural security through: The Messenger of Islam's statement of the tolerant values of Islam. It also aims to highlight the positive attitude of the Holy Qur'an towards what happened to Islam and Muslims in terms of distortion, alteration and distortion by Orientalism and Orientalists, in realization that the truth is the most important cognitive basis for Islamic systems. And defining the criteria for cultural security in Islamic systems. The research came in four sections as follows:

Concepts of cultural security in the modern era. and, The second topic: Cultural security, its values and meanings $17 Y$ 
connotations. and, the implications of the values of the Islamic systems. and, the foundations on which cultural security is built and built.And the researcher in this paper wants to draw the reader's attention to the importance of cultural security. This importance is increasing day by day with the development of the need for security, as the last research came under the title: (Cultural Security and its Values and Foundations Implications), and in this research the researcher focused on the fact that cultural security has values, connotations and foundations that make it capable of organizing society mentally and spiritually. And physical, and works to maintain the balance, stability and unity of the social order.

يتطور الإنسان وتتطور معه الهفاهيم الهتعلقة بخصائص الإسـلام و لا يخلو التاريخ الإسلامسي من الهعارك باسـم الحرية التي تعد مبدأ مـن الهبادئ الإسـلاميـة النبيلة. تتلحضص مشكلة البحث في السؤال التالي: هل يهكن وضـع دراسـة مقارنة في خصسائص الإسـلام مـع غيره مـن الديانات السماوية وذلك في خطوة مقارنة في تطور الفكر الإنساني وخصائص الفكر الإسلامي و الفكر الغربي فيهما يتعلق بالخصائص؟

$$
\text { أههم التساؤ لات: }
$$

س-هل يهكن وضع مقارنة بين حدود خصائص الإسلام ما بين الفكر الإسـالامي و النظم الغر بيـة الهعاصرة

أهمية الببحث وأسباب إختياره:

كل فعل من الأفعال الإنسانية لا بـ أن يخضع لفلسفة خلقيـة بهـا تتضهنه مـن معايير وقيهم يحتكم اليها الفرد في التهمييز بين الفضيلة و الرذيلة وبين الخير والشر؛ وذذك لأن صفات الأفعال تنسب إلى الغايات الهـرغوب تحقيقها ويتميز النظام الإسلامي بأحكام ذات قيم فاعلة تهتم 
بتوجيه تحقيق الأمن الثقافي من حيث الأهميـة أما من حيث الأسبـاب i

ا-يهتم البحث بإظهار جانب من جوانب حكمهة تحقيق الأمن الثقافي في الأر ض.

ب-يبرز وظيفة المسلهم تجاه نفسه ومجتمعـه حتى تعود النظم الإسـلامية

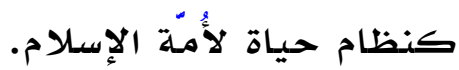
ץ-سبب إختيار هذا العنوان: دفعتتي رغبتي في الوقوف على ما كتبـه أهل العلم عن الأمن الثقافي. أهداف اللدراسة:

ان الهدف الرئيس مـن هذه الدراسـة هو تسليط الضوء على النظم الإسلاميـة ودورها في تحقيق الأمن الثقافي. والتي ينبغي أن تتوفر في أي مجتمع مثقف ومنظم تسود فيه ثقافة الإسلالام، حتى تتم الإستفادة من النظم الإسـلاميلة على الوجه المأمول. و لتحقيق هذا الهدف فإن الدراسـة الحالية تسعى لتحقيق الأهداف الفر عيـة الاتية:

ا. بيان الأسس التي بني عليها تحقيق الأمن الثقافي مـن خلال بيان

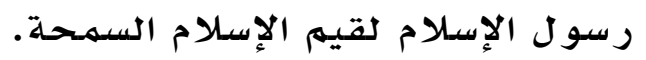

r. إبراز الهوقف الإيجابي للقر آن الكريهم تجاه ما طرأ على الإسلام

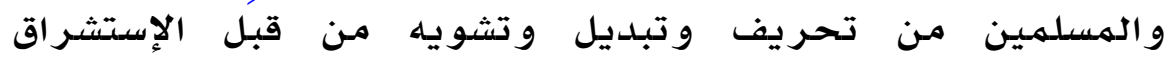

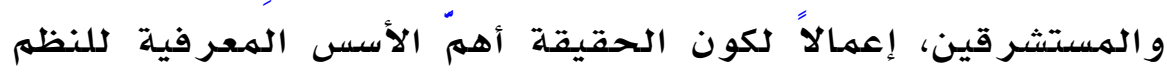

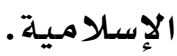
r. تحديد قيم و معايير تحقيق الأمـن الثقافي في النظم الإسلاميـة. حلدود الدراسة:

هذا النوع من الأبحاث تتداخل فيه الكثير من الهسائل، والتي لا يسعف الهقام للتفصيل فيها؛ لطبيعة الأبحاث العلمية المسكمة، ورمن الهسائل الطويلة التي لها تعلقاتها بهذا البحث: خصائص الإسلام ودورها 
في تحقيق الأمـن الثقافي، وهي مـن المسـائل المههمة التي تحتهل كل مسألة منها تأليفاً خاصاً؛ إلا أن حدود هذا البحث تظهر في إبراز خصائص الإسلام ودورها في تحقيق الأمن الثقافي وما دل عليه ذلك من خلال النظم الإسـلا ميـة

أسئلة البحث: يطرح الباحث عدة تسـاؤ لات أهمها:

ا- - مـا مفهوم الأمن الثقافي و خصائص الإسـلام ؟ ץ- مـا دور تحقيق الأمن الثقافي على هذه القيه؟ ب- مـا مدى ارتباط خصدائص الإسلام بعقيدة التوحيد، و الأخلاق

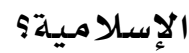
ع- مـا الأسس التسي بنيت عليها خصائص الإسلام ؟

منهج البحث:

بغية تحقيق الأهداف اعتمدت الهنهج الوصفي التحليلي؛ لوضع الأفكار في سياقها السليه، وتحليلها وربطها ببعضها البعض، لبيان التشاكل و التمـايز بين موقف الإسلام و المسلمين من الأمسن الثقافي، وموقف الأبحاث النقدية و الدينية الحديثة في الغرب.

تبويب البـحث:

تضهـن هذا البحث: توطئة: وتهدف إلى إيضـاح مفهوم خصائص الإسـام ودورها في تحقيق الأمن الثقافي، وإيجاد اطارٍ منهجي يحكم جزئياته وفق النظم الإسـلاميـة، وبيان أهمية الأمن الثقافي من حيث إثن

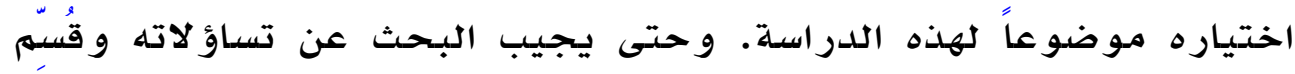
البحث إلى ثلاثة مبـاحث وهي كالآتي:

المبحث الأول: النظم المفاهيي والدلات: الهطلب الأو ل: التعر يف بهصطلحات الدراسلة. المطلب الثاني: مفهوم الأمن. 
الهطلب الثالث: الأمـن الثقافي ودلالته في التشريع الإسـلامي. المبحث الثاني: دور النظم الإسعلامية في تحقيق الأمن الثقافي: الهطلب الأول: دور الأمن الثقافي ودلالات خصائصسه. الهطلب الثاني: دور كلهمة قيم (خصائص). الهطلب الثالث: دور الوسطية في تحقيق الأمـن الثقافي. المبحث الثالث: تأثير خصائص الإسلام في تحقيق الأمن الثقافي: الهطلب الأول:تأثير خصدائص الوضوح مـع رفع الحرج والربانيـة، في تححقيق الأمـن الثقافي. الهطلب الثاني: تأثير خصسائص الإنسانية والعالميـة والتكامل والتناسق مـع الوسطية، في تحقيق الأمن الثقافي. الهطلب الثالث: تأثير خصائص الثبات والهـرونة، الإيجابية و الواقعية، في تحقيق الأمن الثقافي. الخاتهمة: و فيها أهم النتائج و التو صيات و قائهمة الهصادر و المـر اجـ. 
المبحث الأول: النظم المفاهيم والدلالات:

المطلب الأول: التعريف بمصطلحات الدراسة:

مصطلحات البحث:

التعريف بالنظم في الإصطلاح: (كل مات بتعلق بالترتيبات

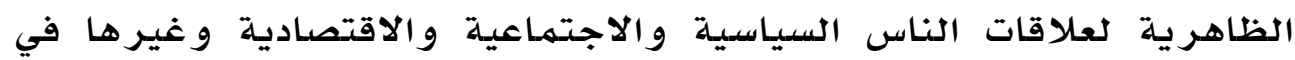

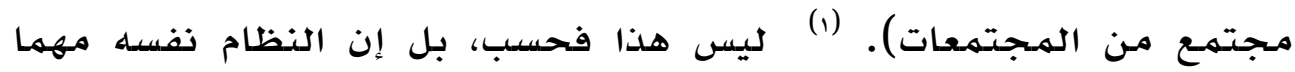
كان نوعه لا يتأتى إلا بقدر من هذهئه الهن الخصائص.

اللدور: معنى الدور في اللغة: قال ابن فارس: الدال و الواو و الراء أصل الدل

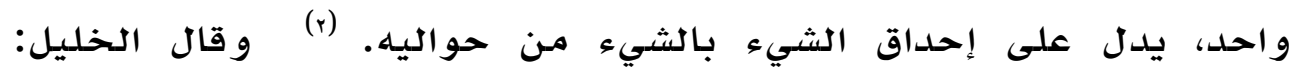

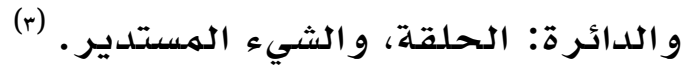

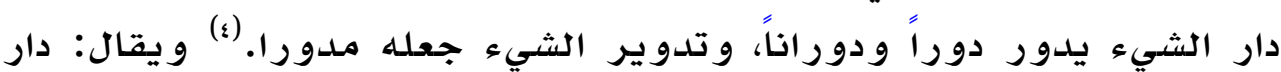

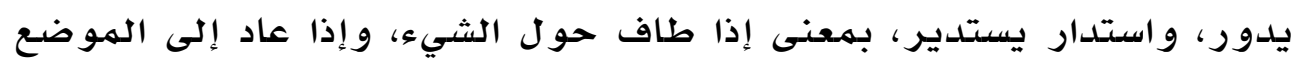

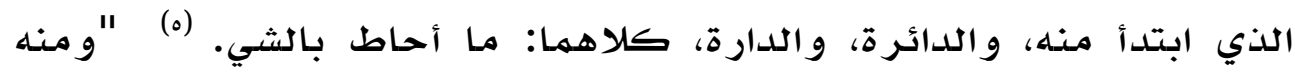

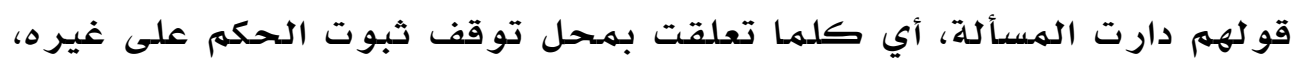

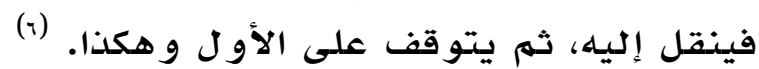
$\square$

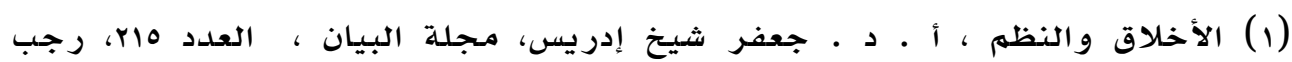

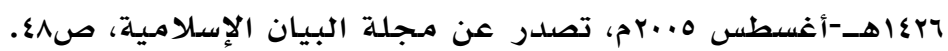

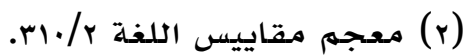

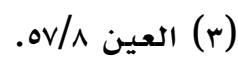

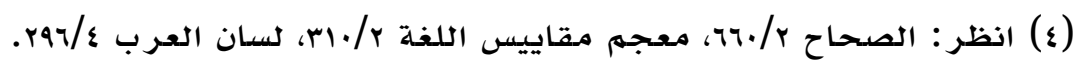

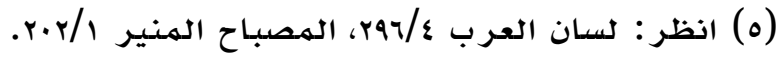

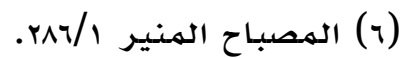




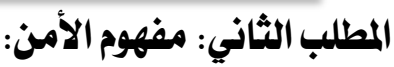

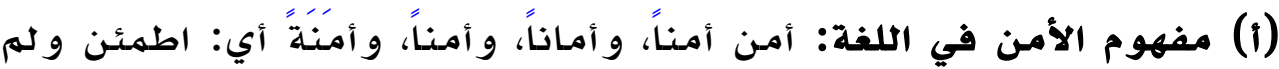

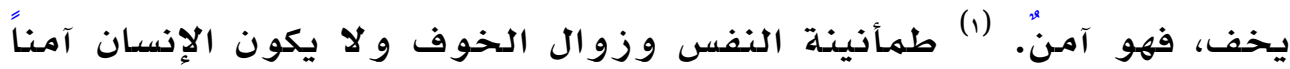

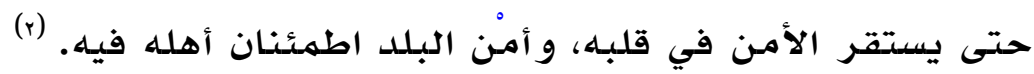

\section{(ب) التعريف بالأمن في الإصطلاح:}

هو عبارة عن الإجراءات الأمنية التي تتخذ لحفظ أسرار الدولة

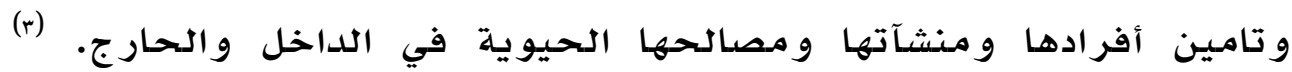

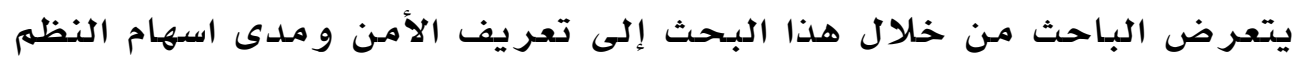

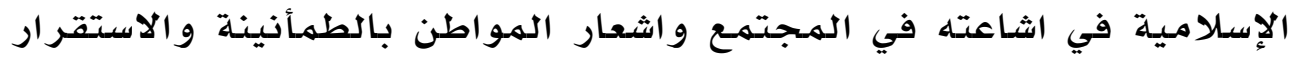
و أعني الاستقرار الفكري، كما يحاول الباحث أن يوضح مديه مدى مسؤو لية

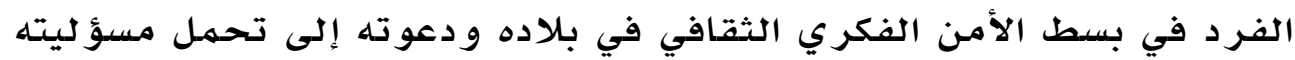
كاملة وبالتالي الإسهام في تحقيق أمن الدو للة الإسهلامية. ان للنظم الإسلامية أهدافا تريد تحقيقها و لا بد لكأمن الثقافي ان

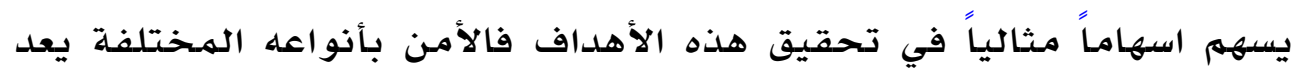

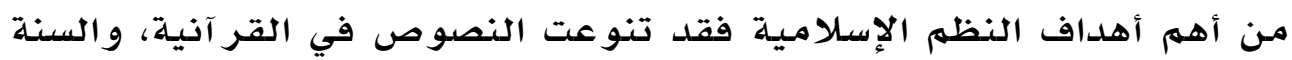
النبوية وهما أهم اسـاسين يقوم و يبنى عليها الأمن الثقافي والتمكين إليه.

(1) المعجم الوجيز، مجمع اللغو العربية، د. ط، (مجمع اللغة العربية، القاهرة .1.rم)، صـro

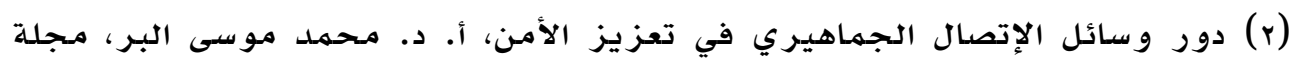

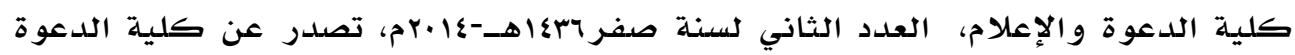
و الإعلام، بجامعة القر آن الكريم و العلوم الإسلامية، صــاها.

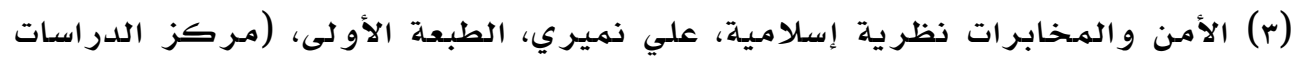
171

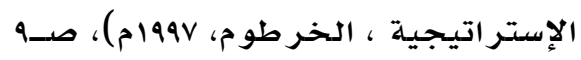


(1)

أمن أمناً، و أمـاناً، و أمناً، و أمَنَة أي: اطهئن و لهم يخف، فهو آمنه.

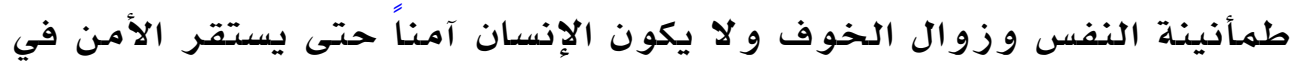

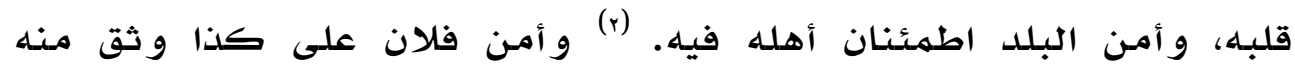

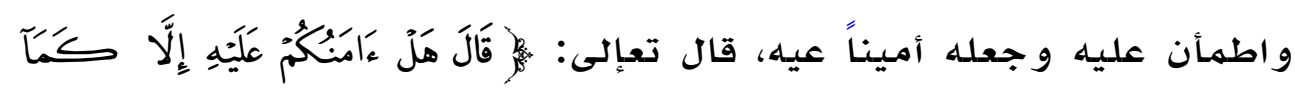

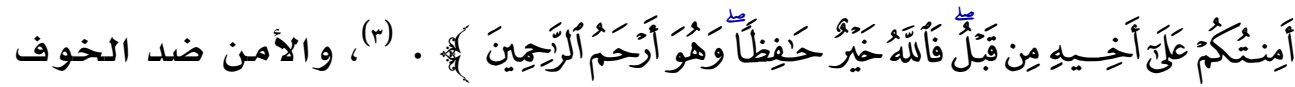

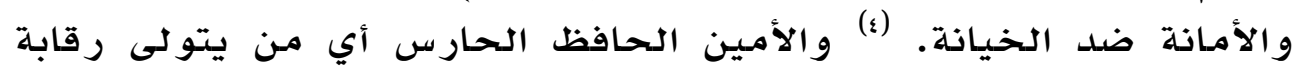

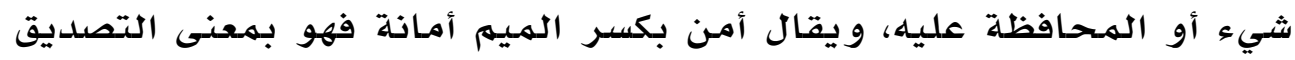

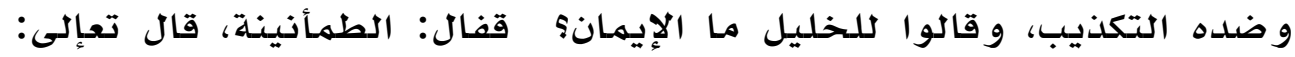

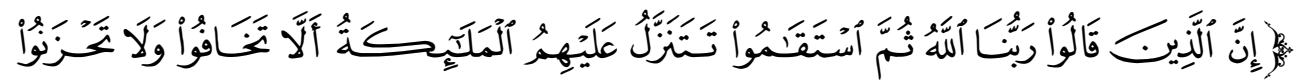

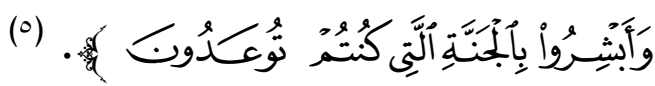
وهو عبارة عن الإجراءات الأمنية التي تتخذ لحفظ أسرار الدولة

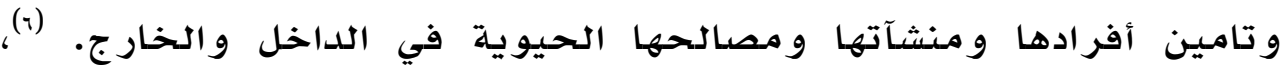

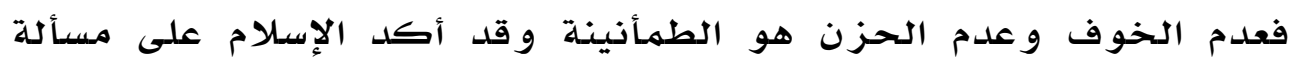

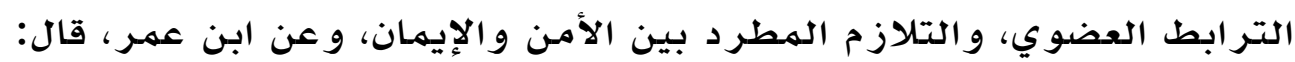

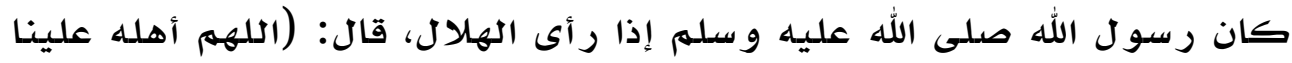

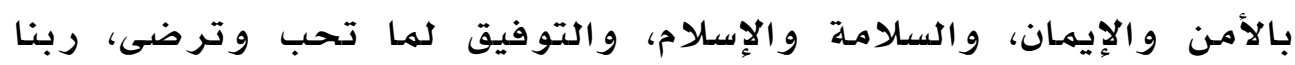
(1) المعجم الوجيز، مجمع اللغو العربية، د. ط، (مجمع اللغة العربية، القاهرة •l+rم)، صـr

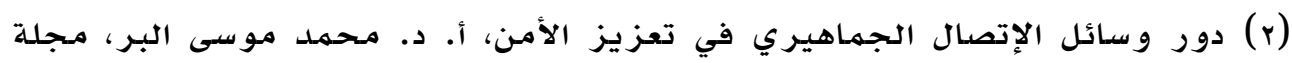

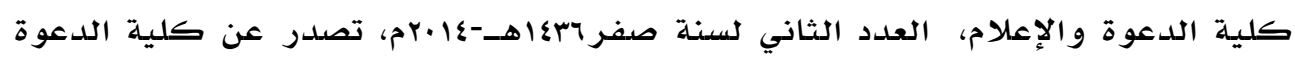

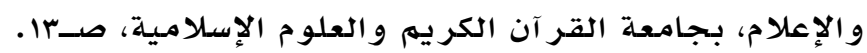

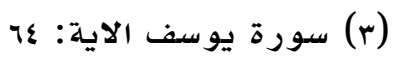
(ع) لسان العرب، ابن منظور أبو الفضل جمال الدوالدين،الجزء الأول (دار إحياء التراث

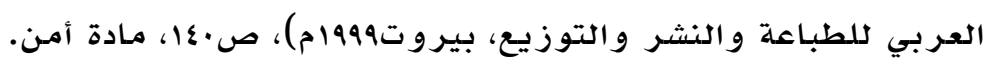

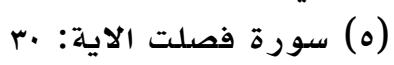

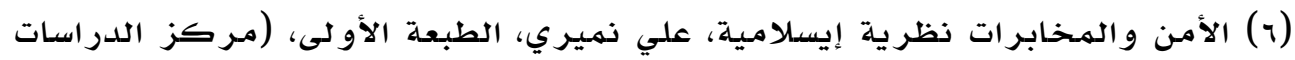
179

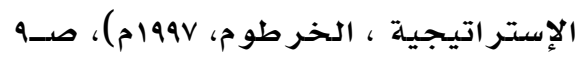


وربك الله). (1) حيث ان فصل احلدهما عن الآخر يؤدي حتهماً إلى اذاقة تلك الأمهة لباس الخوف و الجوع و الضنك و الهوان.

ويعرف أ. د. محهمد موسى البر الأمن بأنه: (إحسساس الفرد

و الجماعة بإشباع دو افعهما الهعنو يـة والبشرية و النفسية و على قمهة هذه الدوافع دافع الأمن بمظهريه الهمادي والحسي النفسي، المتهثلين في اطهئنان المهجتمـع ثقافياً بتوفير أسبـابه المـادية كالسكن الدائم المستقر و الرزق الجاري والتوافق مـع غيره، والدوافع النفسية المتمثثلة في اعتر اف الهجتهـع بالفرد ودوره ومكانته فيه وهو ما يهكن أن يعبر عنه بلفظ

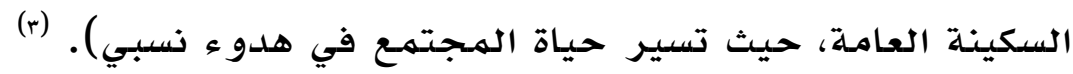
الأمـن هو من الجهد المنظم الذي يصدر عن الجمـاعة لإثباع دوافع أفرادها، أو رد العدوان عنهم أو عن كيـان الجماعة ككل، وتضطلع بـ قيادة الجماعة وهذا الذي يعرف بالأمن الإجرائي، وهناك الأمن الجنائي و الأمـن العام ومـن الأمن الداخلي، وهو الجهود التي تبذلها الدو لة لتثبيت التيت الشعور بالأمن لدى المهواطنين بالعمل على منـع أو التقليل من فرصة ارتكاب الجر يهمة وتتبـع مـرتكبيها و ضبطهم وجهـع الأدلة و تقديهها للقضاء. ويهكن أن نقول إن الأمن هو الحالة التي تتوافر حيث لايقع في البـلاد اخلال بالنظام أو في جرائم يعاقب عليها أو صورة نشاط خطر يدعو إلى اتخاذ تدابير الوقايلة والأمـن حتى يهـنع النشـاط الخطر مـن ان يترجم نفسـه إلى جريمهة مـن الجر ائم.

(1) صحيح ابن حبان ، كتاب الرقائق باب الأدعية ، ذكر ما يقول المرء إذا رأى الهلال أول ما ير اه حديث رقهم : (r) المفهوم الأمني في الإسلام، علي بن فائز الجحني، مـجلة الأمن مـجلة أمنية محكمهة،

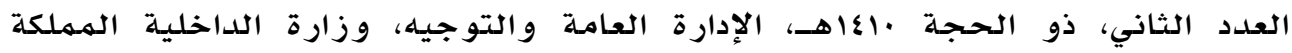
العربية السعودية، صـ1017) (r) دور وسائل الإتصال الجماهيري في تعزيز الأمس، أ. د. محهمد موسئ موسى البر، مجلة IV. كلية الدعوة والإعلام مرجع سـابق، صــأ. 
لأهمية الأمـن في خصائص الإسلام نجد أن العلامهة أبا الحسن الهاوردي تعرض لهوضوع الأمـن في معرض حديثه للوازم حفظ الهـتهـع و الهعتقد حيث قال: تحصين الثغور بالعدة الهـانعة والقوة الدافعة حتى لا يظهر الأعداء بثغرة ينتهكون فيها محرماً أو يسفكون فيها لمسلهم أو معاهد دماً إلى أن قال: ان صلان الإنسانيـة يقوم على قواعد: منها ايمان يكبح شهوتهم، سلطة يـر هبوذها، أمـن عام، عدل شـامل، خصب دائهر، أهل فسيح.

الناظر في تدابير الأمن كقيهة من خصدائص الإسلام يجد أن

الححدود التي شـرعها الله والقصاص الذي أوجبه والتعازير التي سنها تهدف إلى حماية المجتمع ووقايته مـ المهخاطر وجرائم الحدود الثهاني: الحرابة والقذف، البغي والزنا، شرب الخمر و الردة، السرقة والتعزير، و جر ائم التعازير هي القتل العمد، والقتل الخطاً و القتل شبـه العمد وجر ائم التعازير متتنوعة ومتفاوتة كلها تهدف إلى حفظ الأمن في النظم

الإسـالا ميـة.

\section{: (جד) الثقافي: مفهوم الثقافة :}

ترجع دلالة الثقافة في اللغة إلى الحدذق، والفهه، وسرعة التعلم،

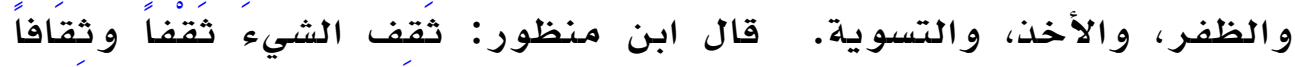

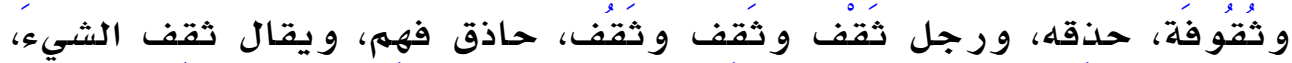

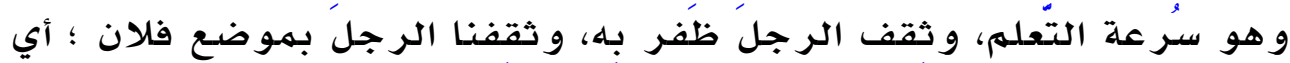

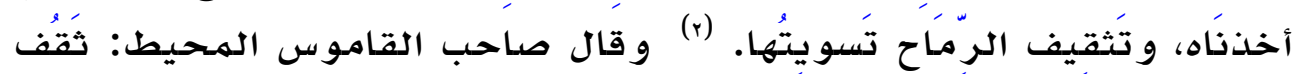

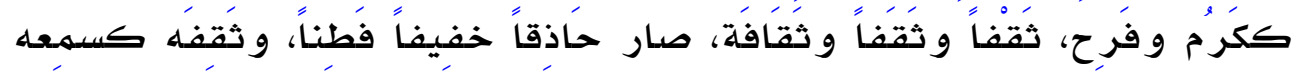

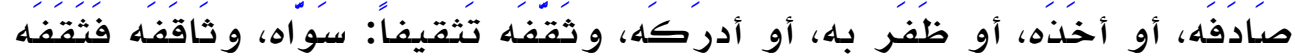

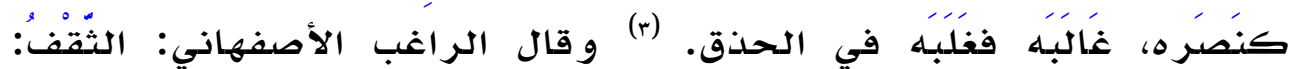

(1) الأحكام السلطانية و الو لايات الدينية، علي بن محمد حبيب البصري الماوردي، د. ط

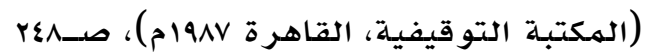

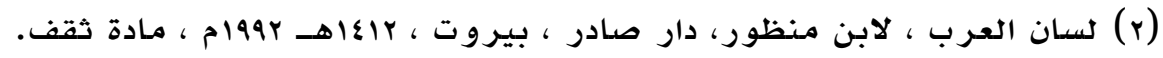

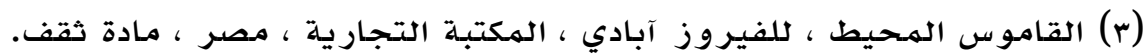


الحذقُ في إدراكَ الشيء و فعله، وومنه استُعير الهُثَاقَفَة، و يُقال: ثَقفتُ كذا

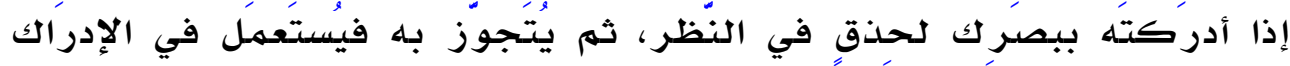
و إن لهم تَكُن معهل ثَّافَة.

أمـا في الاصطلاح فقد تعددت مفاهيهم الثقافة تبعاً لهوقع رؤية كل مدرسة اهتهـت بها و بهـا يُعد من مكوناتها، إلا أننا نريد بها في مقالنا هذا : طبيعة الرؤية التي تتحكم في الهرء فيأتي ما يأتي في حياته، و يذر مـا يذر، منطلقاً من مـلامح عقليـة تميز سيروروة حياته . الاطلب الثالث: الأمن الثقافي ودلالته في التشريع الإسلامي:

لقد تطور مفهوم الأمـن الثقافي في العصر الحديث مهما جعل النظم

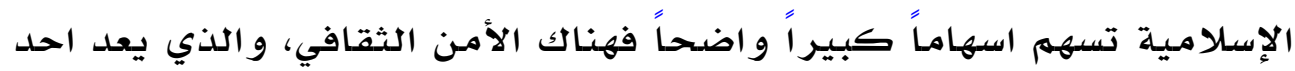
جوانب الأمـن القومي الذي يشهل ايضاً الأمـن الإجتهماعي و العسكري و السياسي والإقتصادي يتفرع عنه الأمن الغذائي وسوف يتناول الباحث بالدراسـة كل من الأمسن الثقافي و الغذائي و العسكري و ويمكن للنظم الإسلاميلة أن تسههم في أنواع هذه الأقسـام من الأمـن في الدولة الإسـلاميـة كها في تفسير السعدي عن الآيات أدناه.

أولاً: الأمن في القر آن الكريه: نورد النصوص القر آنيـة التي تناو لت الأمـن في القر آن الكريهم في عرض الآيات كهما يلي:

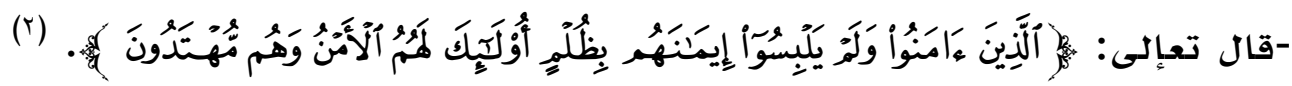

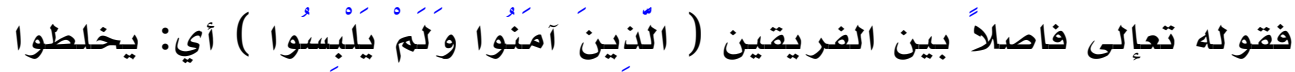

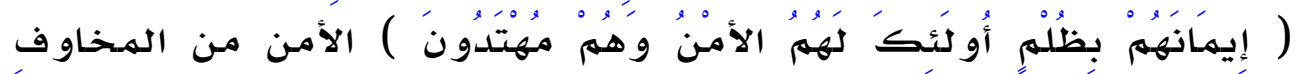

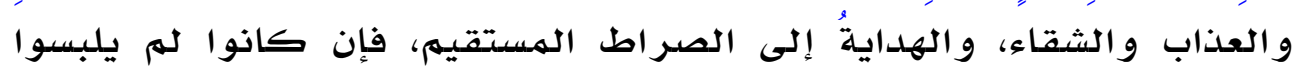
إيهاذهم بظلم مطلقا، لا بشرك، و لا بهعاص، حصل لهم الأمن التام، و الهداية

(1) معجم مفردات ألفاظ القر آن ، الأصفهاني ، تحقيق نديم مر عشلي ، دار الفكر ،

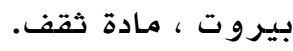

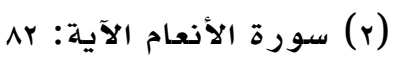


التامهة. وإن كانوا لهم يلبسوا إيهانهم بالشرك وحده، و لكنهم يعملون السيئات، حصل لهم أصل الهداية، و أصل الأمن، وإن لهم يحصل لهم كهـالها. و مفهوم الآية الكريهـة، أن الذين لهم يحصل لهم الأمران، لهم يحصل لهم

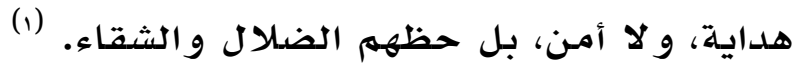

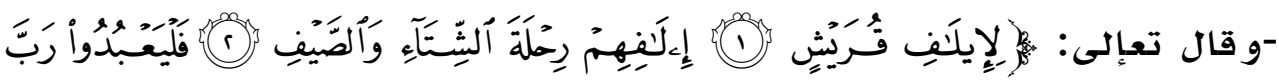

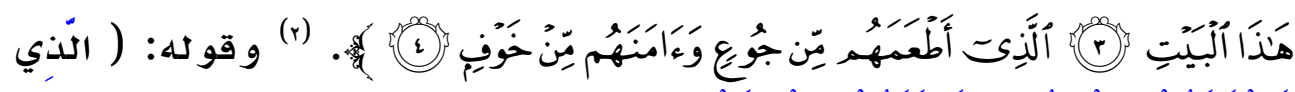

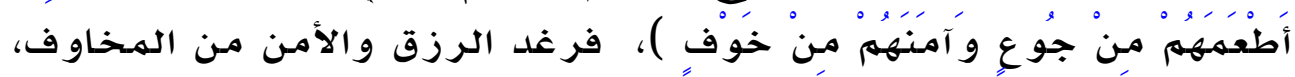

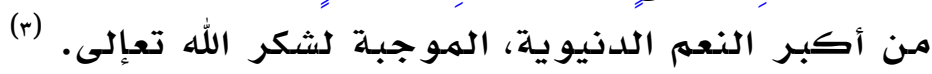

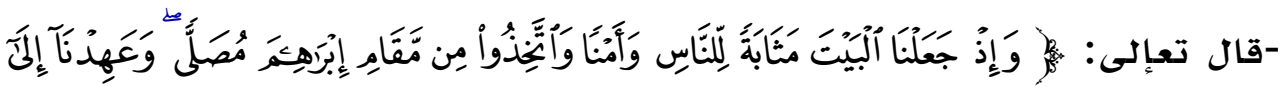

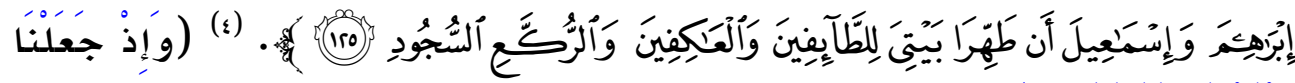

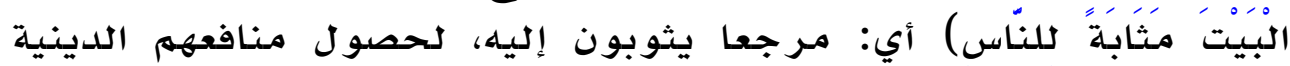

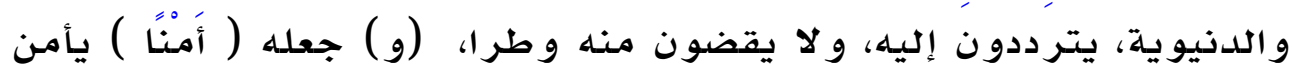

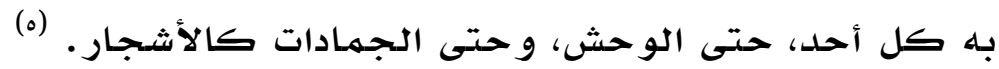

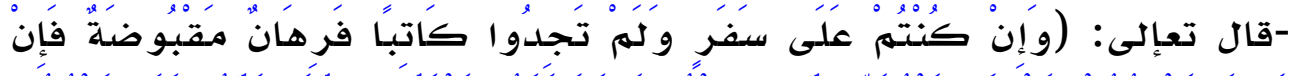

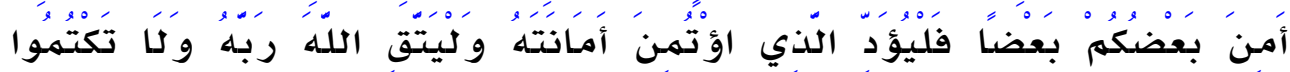

(1) تيسير الكريم الرحمن في تفسير كام المنان، عبد الرحمن بن ناصر بن السعدي،

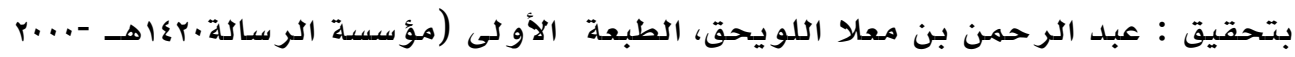

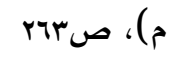
(r) سورة قريش الآيات: (r) (r) (r)

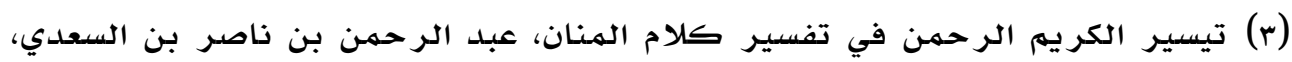

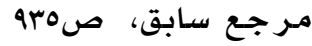

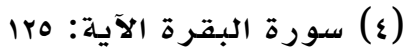

(0) تيسير الكريم الرحمن في تفسير كلام المنان، عبد الرحمن بن ناصر بن السعدي، 


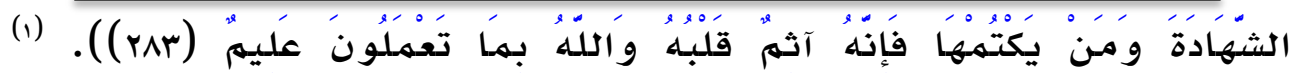

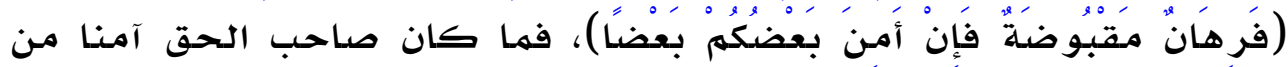
غريمـه وأحب أن يعاملـه مـن دون رهن فعلى مـن عليه الحق أن يؤدي إليه

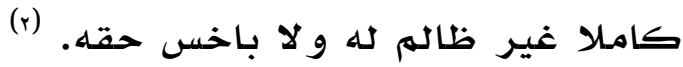

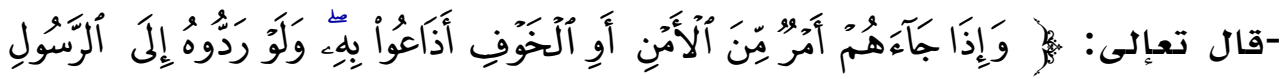

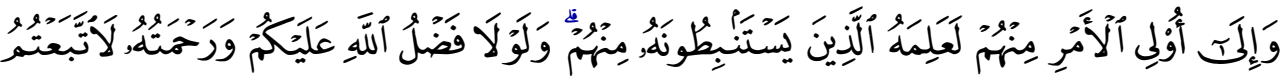

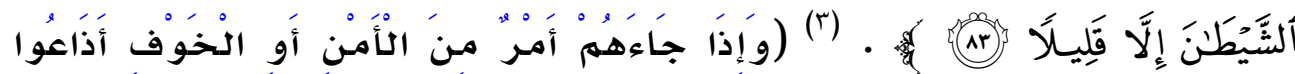
بِه)، فهذا تأديب من الله لعباده عن فعلهم هذا غير اللائق. و أنه ينبغي لهم إذا جـاءهم أمـر مـ الأمور الههمهة والهصدالح العامـة مـا يتعلق بالأمـن وسرور الهمؤمنين، أو بالخوف الذي فيه مصيبـة عليهم أن يتثبتوا وولا يستعجلوا

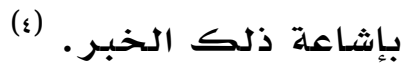

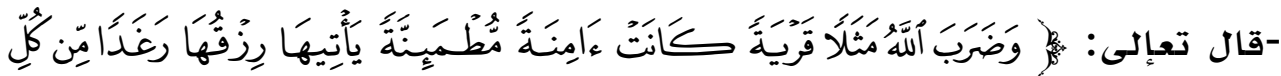

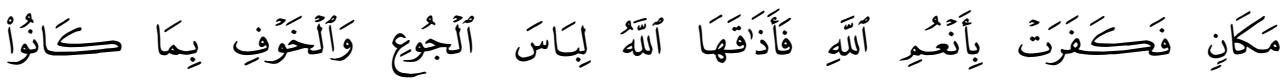

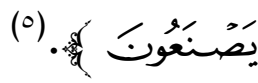

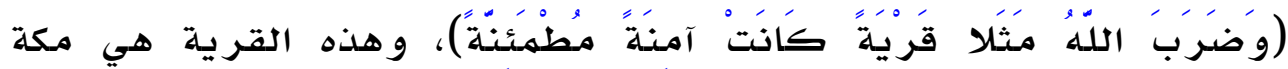
المشرفة التي كانت آمنـة مطمئنة لا يهاج فيها أحد، وتحتر مها الجاهلية الجهاء حتى إن أحدهم يجد قاتل أبيـه و أخيـه، فلا يهيجـه مـع ثدة الحميـة

(1) سورة البقرة الآية: (ץ) تيسير الكريهم الرحمن في تفسير كارة الام الهنان، عبد الرحمن بن ناصر بن السعدي، مرجـع سابق، ص119 (r) سورة النساء الآية: (ع) تيسير الكريه الرحمن في تفسير كاءم المنان، عبد الرحمن بن ناصر بن السعدي، 
فيهم، و النعرة العربية فحصل لها من الأمن التام مـا لهم يحصل لسواها

و كذلك الرزق الواسـع. (1)

وهكذا نجد ان كثير مـن الآيات القر آنية تناولت خصائص الإسـلام ودور ذلك في تحقيق الأمن الثقافي.

(1) تيسير الكريه الرحمن في تفسير كام الهنان، عبد الرحمن بن ناصر بن السعدي،

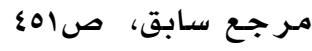
IVo 
المبحث الثاني: دور النظم الإسلامية في تحقيق الأمن الثقافي:

المطلب الأول: دورالأمن الثقافي ودلالات قيمه:

لعل جانب تحقيق الأمن الثقافي من أهم جوانب الأمن القومي لأنه

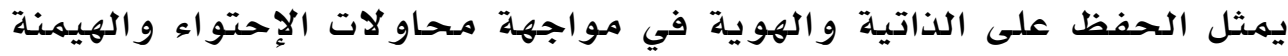

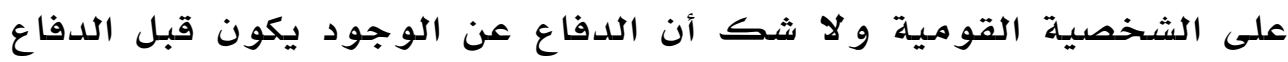

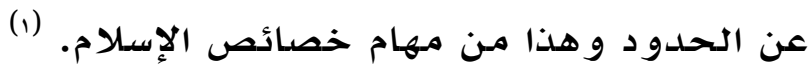

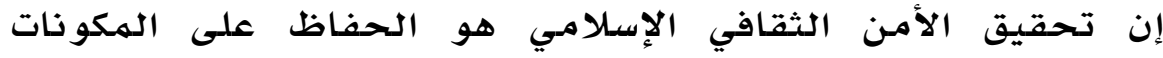

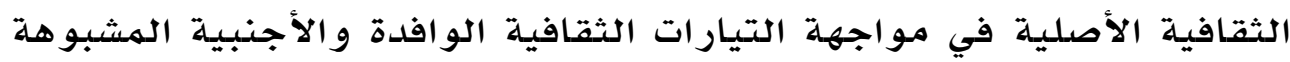

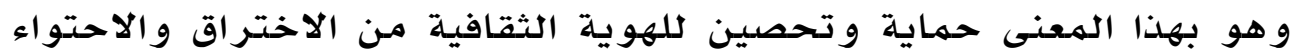

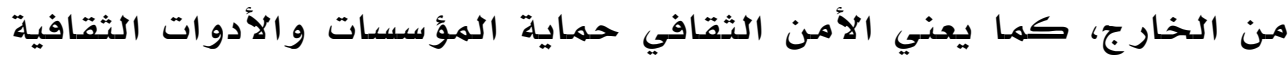

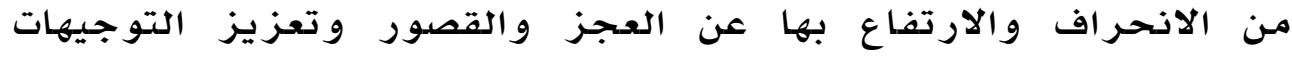
السليهمة وانتقاد التوجهات الشاذة والمتطرفة وهذات ولذا كله يقع على كاهل

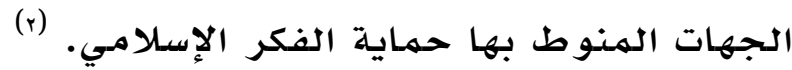
لذلك حققت خصائص الإسلام تحقيق الأمن الثقافي وذلك بحماية

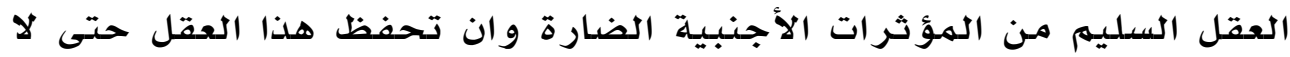
يطال بواسطة موجهات خارجية و لا بد كذلك من حماية خير اته الثقافية

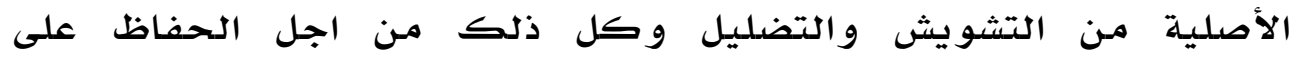

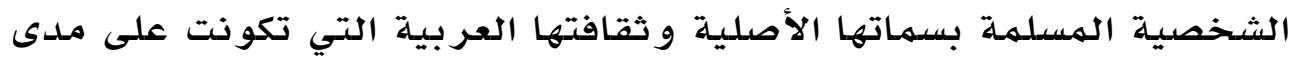
قرون عديدة استتندت خلالها على معطيات الثقافة و الحضسارة الإسلامية.

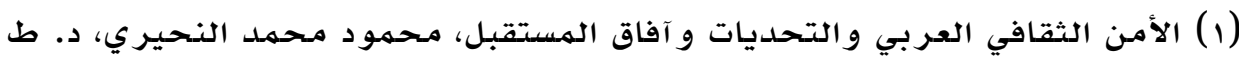

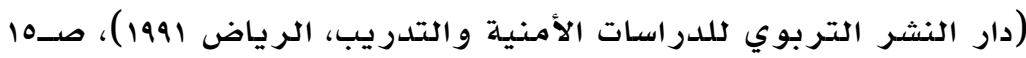

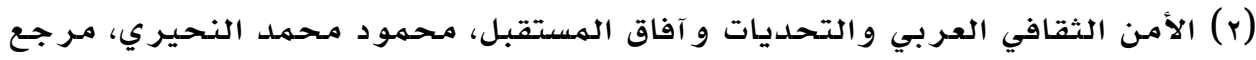
سابق، صد10

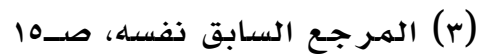




\section{المطلب الثاذي: دور كلمة قيم (خصائص):}

أو لاً: توطئة: القيهم جمع مفرده قيمهة، والقيهمة مفردة من مـادة "قوم" قام الهتاع بكذا إذا تعدلت قيمته بـه (1) والقيمهة الثمن الذي يقاو م بـه الهتاع، أي في يقوم مقامهه، والجمـع القيه، مثلل سلدرة وسلدر(؟)، و في لسـان العرب: القيهم الإستقامهة، والإسـتقامـة إعتدال الشيء و استواؤه وقو له تعإلى

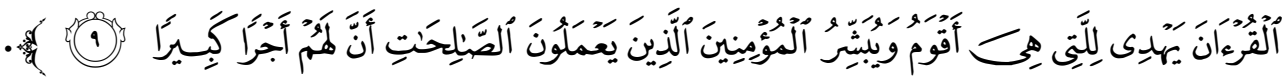
(r) معناه للحياة التي هي أقوم الحالات، وهي توحيد الله تعإلى. (؛) و قواَمُ الأمـر - بـالكسـر - نظامـه و عمـاده، قال أبو عبيدة: هو قواَم أهل

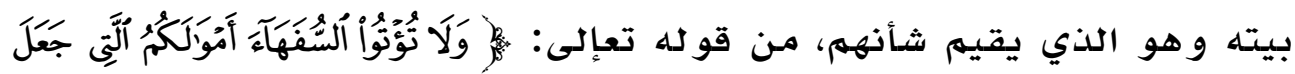

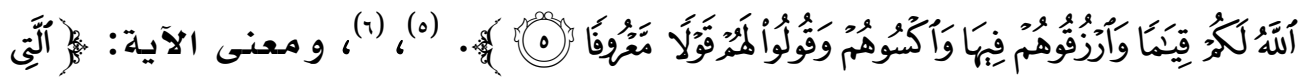

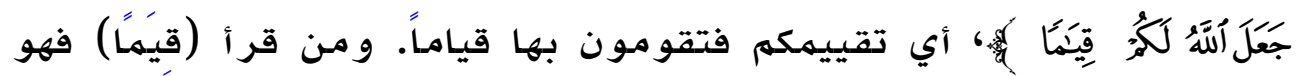
راجع إلى هذا، والهعنى جعلها الله قيهـة الأشياء، فبها تقوم أموركهم.

(1) مختار الصدحاح، محمد بن أبي بكر بن عبدالقادر الرازي، تحقيق: محمود خاطر،

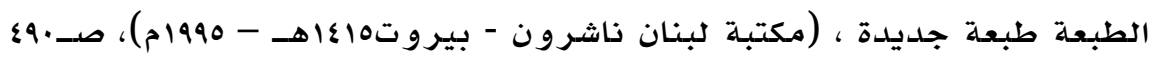

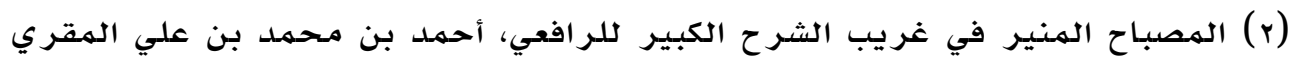

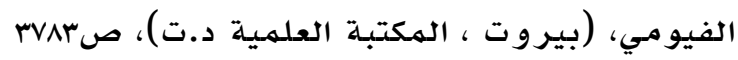

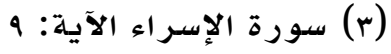

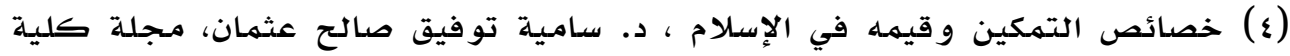

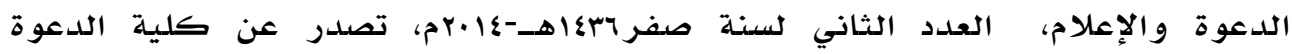

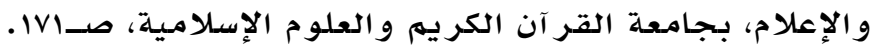

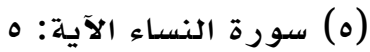

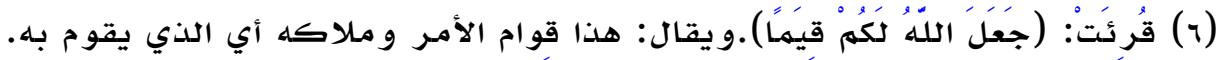

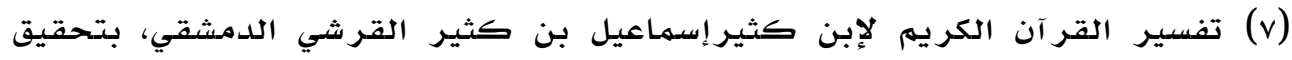

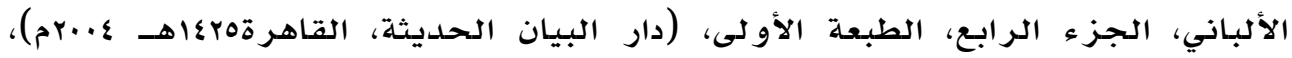




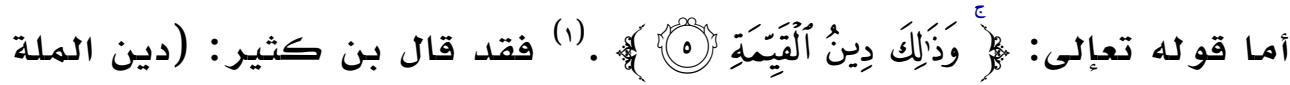
القائمهة العادلة، أو الأمهة المستقيمهة الهعتدلة). (r) و في التفسير الكبير في

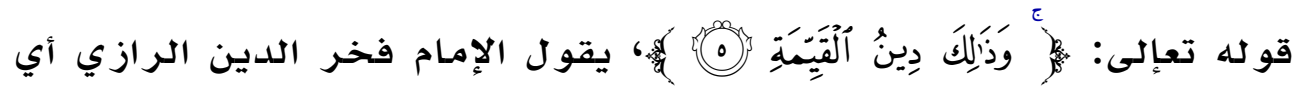
"احكام قيهيـة" أمـا القيهـة، فيهيها قو لان

الأول: قال الزجاج مستقيهة لا دعوة فيها تبيّن الحق من البـاطل، مـن قام يقوم و هو كقوله: قام الدليل على كذا، اذا ظهر واستقام.

الثاني: أن تكون القيمة بهعنى القائمهة، أي هي القائمهة مستقلة بالحجة و الدلالة، مـن قولهم: قام فلان بالأمر يقوم به اذا أجراه على وجهه. (r) و في الهعجم الوسيط: "قيهـة الشيء قدره، وقيهـة الهتاع ثهنه، جمعـه قيه، و يقال مـا لفلان قيهـة: مـاله ثبات ودوام على الأمر ". (؛) و يـلاحظ أن معنى قيهم يتراوح بين هذه الهعاني وهي:

$$
\begin{aligned}
& \text { ا- الإستقامـة. } \\
& \text { r- } \\
& \text { ب- مـا قام بـه الشيء. } \\
& \text { ع- الأحكام القيمهة. } \\
& \text { ه- الدو ام على الأمـر والثبات. }
\end{aligned}
$$

ج- و الإستقلال بالحجة و الدلالة. و لعل اقرب الإستعمالات اللغوية إلى القيهم بمعناها السائد الآن، ما ذكره صاحب القاموس من قولهم:

$$
\text { (1) سورة البينـة الآية: (1) }
$$

(r) تفسير القر آن الكريم لإبن كثير إسماعيل بن كثير الإنـ القرشي الدمشقي، مرجع

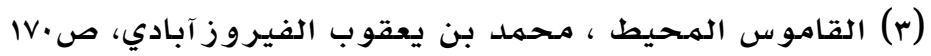

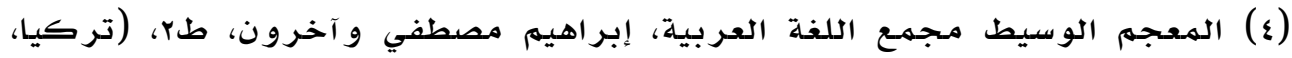

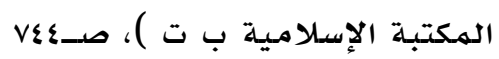


(فلان ماله قيهـة، اذا لهم يلدم على الشيء). (1) و يقول صساحب اسـاس (r)

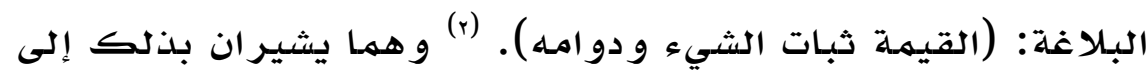
أن القيمهة ترد بهعنى الأمـر الذي يقوم بـ الشيء و الذي يحافظ

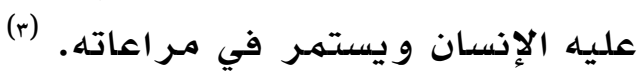
الاطلب الثالث: دورالوسطية في تحقيق الأمن الثقافي:

هذه الخصائص بكل تقسيهاتها تنتظه بشكل متتناسق، لا تتنافر جزئياتها، بل يعلو شكلها الهرهي الخصائص الأسـاسية الهـلزمهة، ثم التي تليها، و هكذا فالهتمسك بأعلى الخصائص كفرد فهو في مرتبة الإحسان، و المـجتمـع الذي يتمسك أفراده بأغلب خصدائص الدين هو الهـتهـع المؤهل

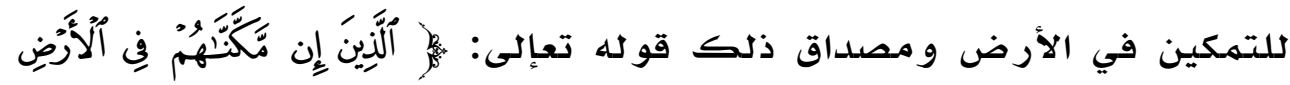

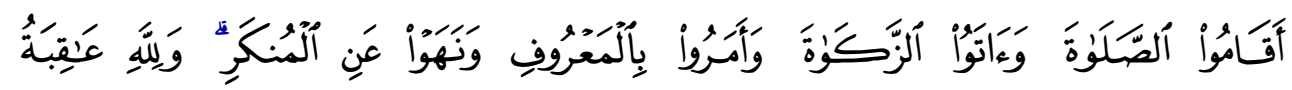

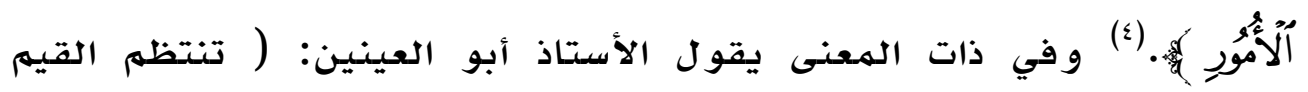
الإسـلاميـة في شكل نسق متكامل فالقيمـة ذات الأهميـة العليا تهثل أعلى قيهم مواضع النسق، وهي تتميز بالثبات والديهومـة، وتحتل القيهم الأقل من أهميـة مـواضع أدنى النسق، وليس معنى ذلك عدم أهميتها، بل هي تحتل

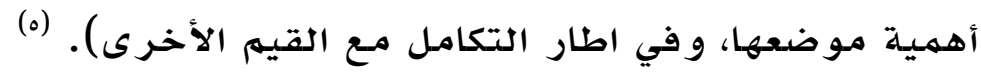

(1) أسـاس البـلاغة، للزمخشري مادة ثقف، (دار صادر، بيروت الطبعة الاولى rاءاهـ OrA_ (199r (r) انظر: القيهم التربوية في السنن النبوية (رسالة دكتوراه)، سمية عبدالهعروف، صـor-or

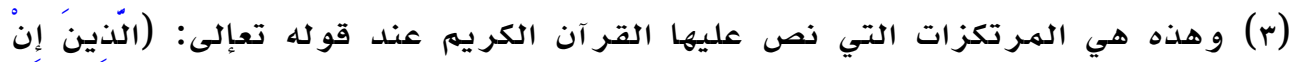

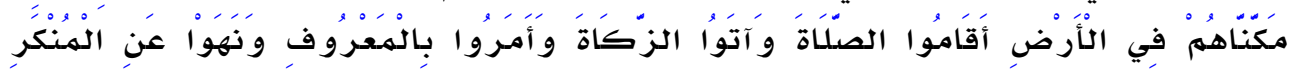

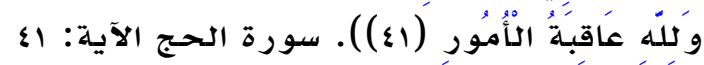

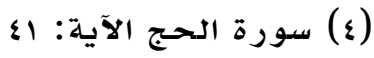


و للتدليل على خصائص الإسلام ودورها في تحقيق الأمن الثقافي،

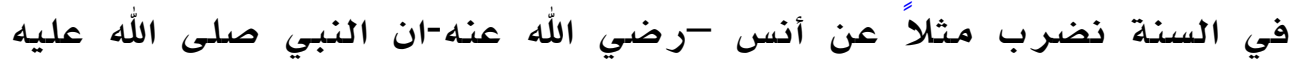

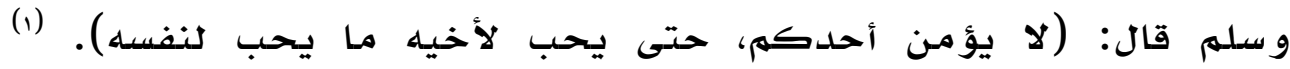

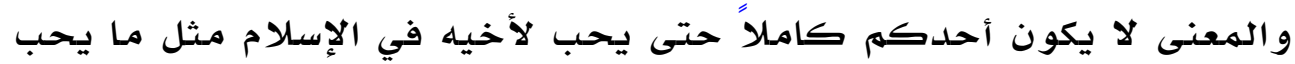

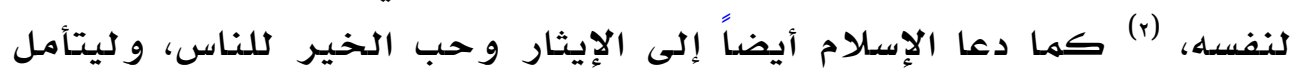

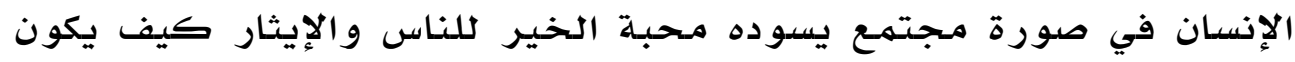

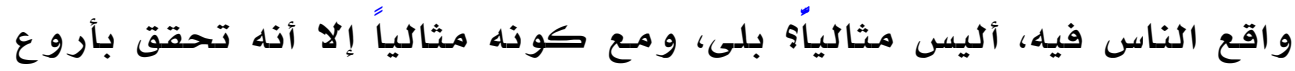

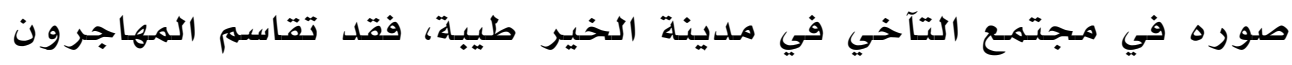

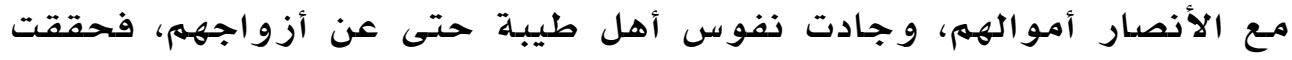

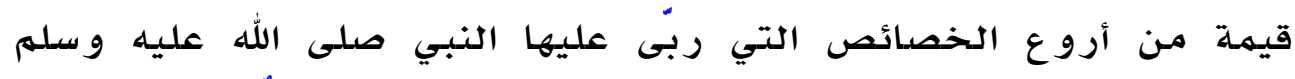

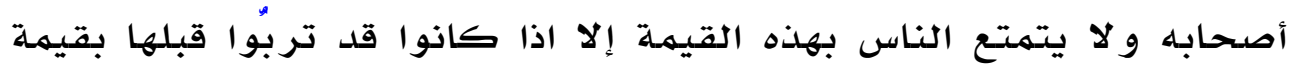
أخرى. (r) ( أهحانه

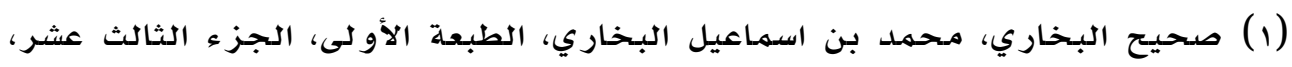

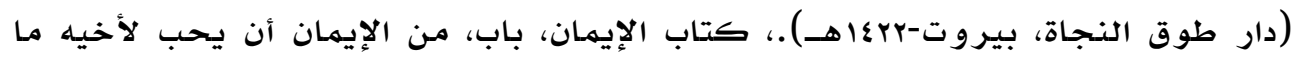

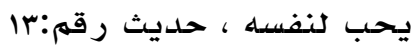

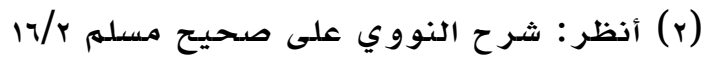

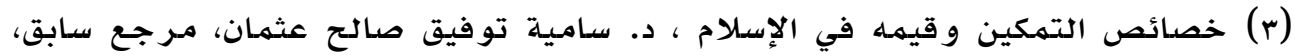
11. 
المبحث الثالث: تأثير خصائص الإسلام في تحقيق الأمن الثقافي:

الاطلب الأول: تأثـرخمائص الوضوح مع الربانية ورفح الحرج في ثتقيق الأمن الثقافي: أولاً: خصسيمة الوضوح: الهـراد بالوضدح هنا، أن خصائص الإسـلام واضحة من حيث الهـر اد منها و الهـر اد بها، فكل الخصـائص على الإطلاق ير اد بها أن يعتقدها الهـرء و يعمل بها طائعاً مـختاراً بقصد طاعة الهولى عزوجل،

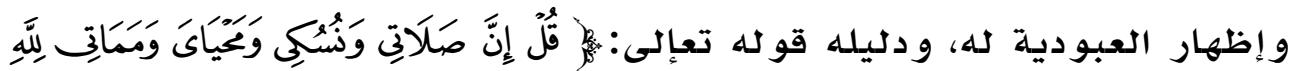

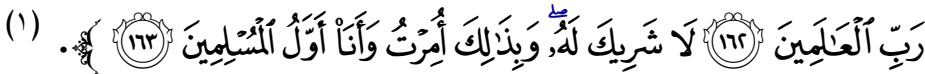
و في الحديث عن عائشة -رضي الله عنها-، أن رسول الله صدلى الله

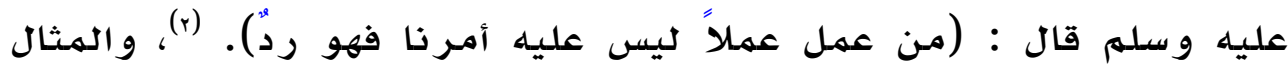
على الوضوح تعلدي الخصائص بنفسها لتحقيق مصلحة الجماعة بعد

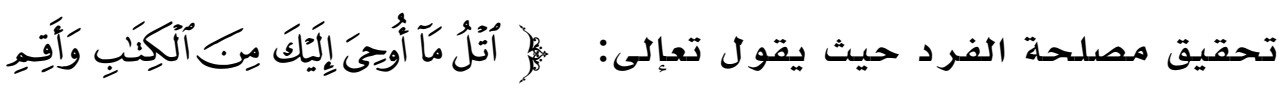

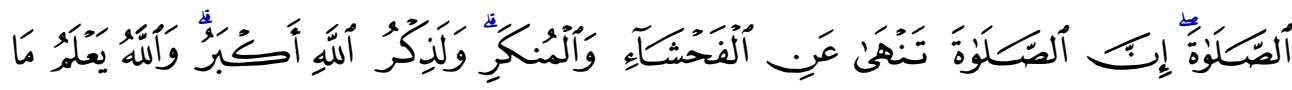

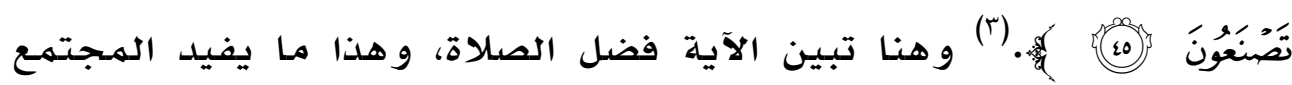
و الفرد وتكون الفائدة أعم، و الهسلهم ينال فضلها و أجر هـا، ويقول تعإلى:

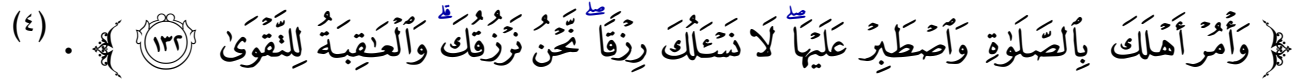
والآية تبين وجوب الأمـر بالصدلاة الهـأمور بها والإستجابة بأدائها مـع

الهمو اظبـة عليها. ثانياً:خصيصة رفع الهرج مع التيسير: و التيسير يأتي بهعنى الوضوح، فإذا ووتح الحكم للهكلفين تيسر عليهم أداء الفعل أو الكف عنه، وذورد قصدة الأعرابي الذي بال في المسجد، فقد ثار عليه الصـحابة، فنهاهم رسول الله

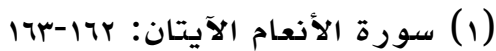
(r) صحيح مسله بن الحجاج النيسابوري، الجزء الثاني، د. ط (دار إحياء التراث

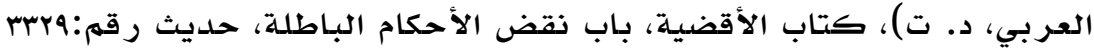

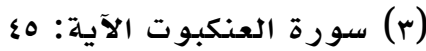

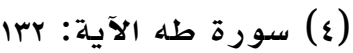


صلى الله عليـه وسلهم بقو له: (دعوه حتى إذا فرغ دعا بهـاء فصبـه عليـ). (1)،

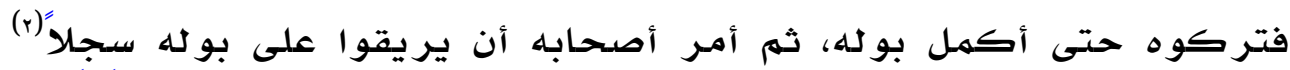

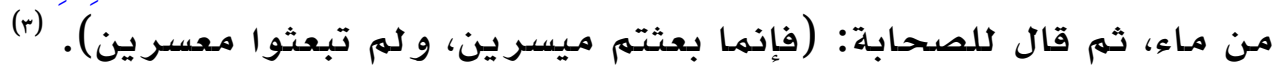
ثم دعا الأعرابي وقال له: ( إن هذه الهساجد لا تصلح لشيء من هذا البول، ولا القذر إنما هي لذكر الله عز وجل، والصلاة وقراءة القر آن). (؛)، و يسر خصائص الإسلام يدل عليه أن التمسك بأصول الديانة يقود مـع حسن النية إلى العهل بكل الديانة، حيث ورد عن ابي هريرة-رضي الله عنـه-قال: (جاء رجل إلى النبي صلى الله عليه وسلهم فقال: ان فلان صلى بالليل، فإذا أصببح سرق، قال (سينهاه مـا يقول).(ه)، قيل ان ان الصدلاة ثلاث خصال، فكل صلاة لايكون فيها شيء من هذه الخصسال تكون ناقصدة، و الخصال هي الإخلاص و الخشية وذكر الله، فالإخلاص يأمره بالهعروف،

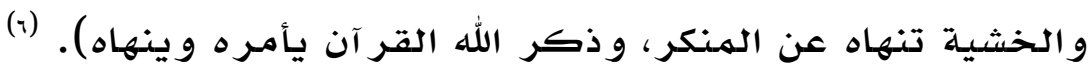

ثانثاً: خصيصة الربانية: تتهيز النظم الإسلامية بأنها تستمد أصو لها وروافدها من مصدر ثابت لاشك فيه فالربانية منسوية إلي الرب جل و علا أو الوحي الإلهي القرآن الكريهم والسنة النبوية المطهرة، فجهيـع جوانب النظم الإسـالامية الفلسفية والتشريعية منبـثقة من تعاليم الإسلام

(1) صحيح البخاري، كتاب الوضوء، باب ترك النبي صلى الله عليه وسلهم والناس

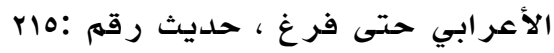

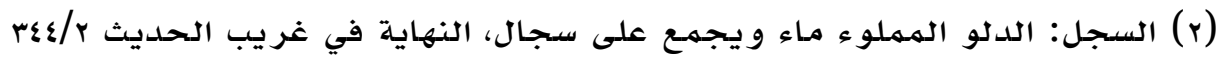

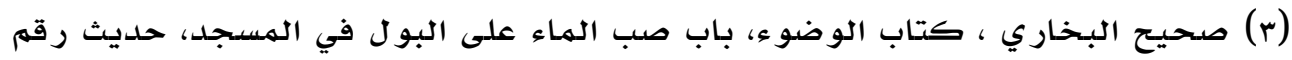
رقا (ع) صحيح مسلهم ، كتاب الطهارة، باب وجوب غسل البول وغيره من النجاسات إذا

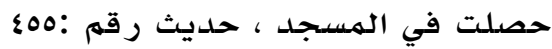

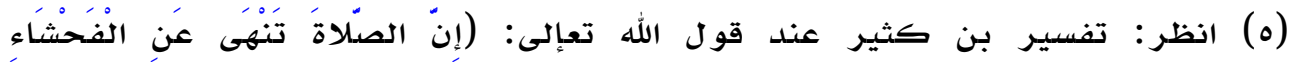

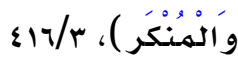
(7) تفسير ابن أبي حاته ، سورة العنكبوت، قوله تعإلى : إن الصدلاة تنهى عن الفحشاء INY و المنكر ، حديث رقم : المين 
و متأثرة بها، ومن ثم فهي ربانيّة الهصدر ربانيّة الحقائق والتصدورات

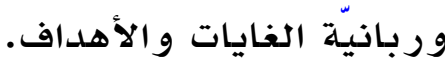

و مـن أهم مظاهر الربانية وحدة الخالق وتنوع الخلق، فالصانع لأيلة آلة يصنعها بتقنية متوازنة تضهن حرية الحركة وجودة أداء العهل لكل جزئية من جزئياتها، والرب أعظم خالق فالهتأمل لـمخلوقات الهولى عزوجل في الكون يجدها متبـاينـة، ومـع هذا التبـاين فإنها تتسق في منظومـة نفعية واحدة تحقق مصلحة الإنسان في الهقام الأول. (1)

ويهكن أن تُوصف خصائص الإسلام من هذه الناحية بأنها ربانية النز عة لأن تصورها للوجود بكل دلالاته ومقوماته مستمهد مـن الله، تلقاه الإنسـان كاملاً بـلالاته هذه ليتكيف بـه ويطبق مقتضياته في حياته، و يعني هذا أن الهسلم يعتقد أن الله خلق هذا الكون وخالق الإنسان ووكل مـافي هذا

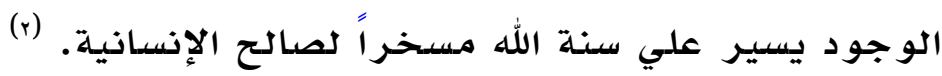
الاطلب الثاني: تأثير خصيصة الإنسانية والعالمية والتكامل والتناسق مع الوسطية، في

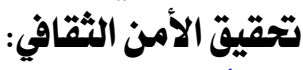
أولاً: تأثير خصيصة الإنسانية والعالمية: إن النظم الإسـلامية إنسانية عامـة لاتفرق بين إنسان و إنسان فهي صانحة لأن تكون ثقافة لكل إنسان بغض إنس النظر عن لونه ودمـه وموطنه، فهي عامـة لجميـع البشر في كل زمان و مكان فليست خاصة بقوم ولا محصورة بهكان ولا مهدودة بزمان، و الإسـلام يحارب كل دعوة عنصرية ويبرأ منها كالفارسية و الفر عونية و غير هـا، فالدعوات العنصريـة تفرق بين النـاس وتجعل الهـجتهـع يتعالي علي

(1) خصائص التمكين وقيمهـ في الإسـلام ، د. سامية توفيق صالح عثمان، مجلة كلية الدعوة و الإعلام، مـرجـع سـابق، صد.

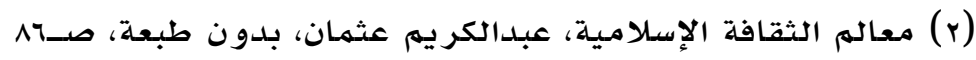


بعضه البعض، وقد حذر الرسول صلى الله عليه وسلهم، علي العصبيـة فقال:

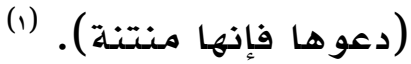

و قال أيضاً صلى الله عليه و سلهم، (ليس منا من دعا إلي عصبية). (r) و من المعلوم أن الإسـلام خاطب الإنسان منذذ بعثة الرسول صدي الله عليـ

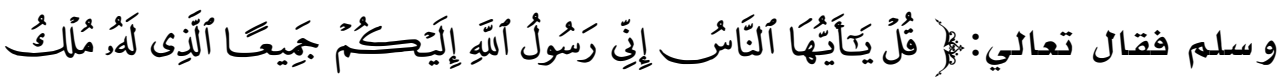

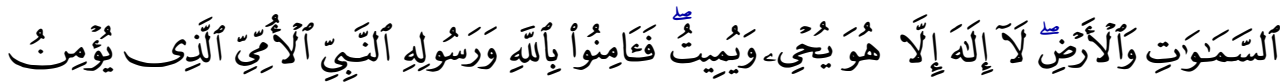

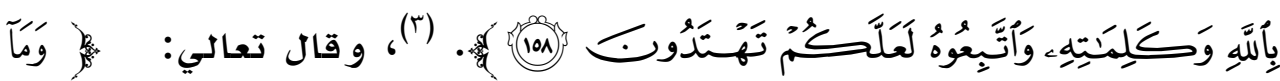

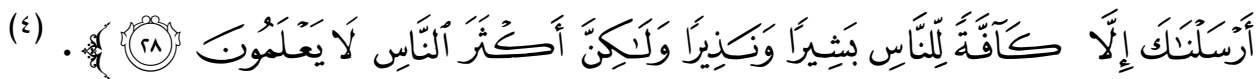
و كانت دعوات الرسل والأنبياء عليهم الصلاة والسلام من قبله

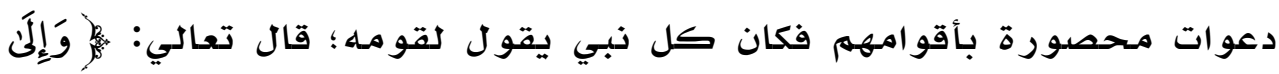

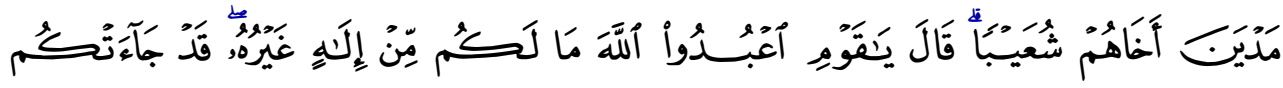

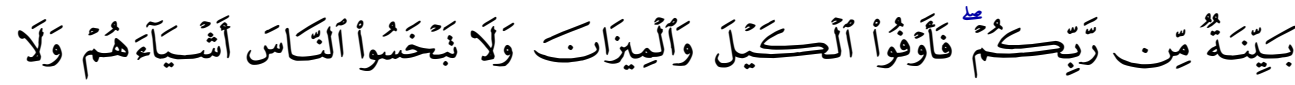

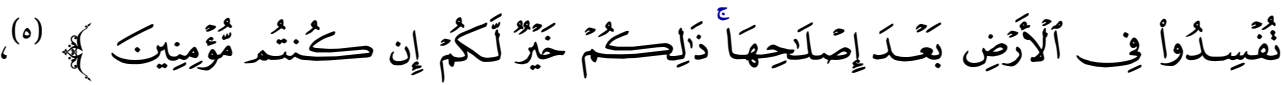

(1) أخرجه مسله، في كتاب البر والصلة باب، باب نصر الأخ ظالماً أو مظلوماً، الجزء

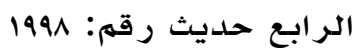
(r) سنن أبي داوود، أبو داوود سليمان وان ابن الأشعث بن إسحاق بن بشير بن شداد بن

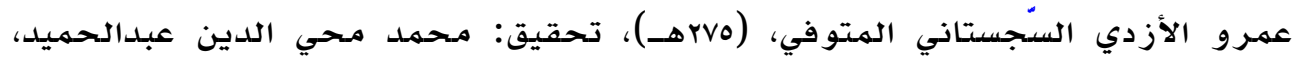

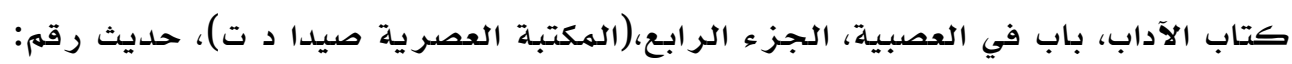
(01Y) صـrr

$$
\begin{aligned}
& \text { (r) سورة الأعر اف الآية: } 101 \\
& \text { (ع) سورة سبأ الآية: } \\
& \text { (0) سورة الأعر اف الآية: } 10
\end{aligned}
$$




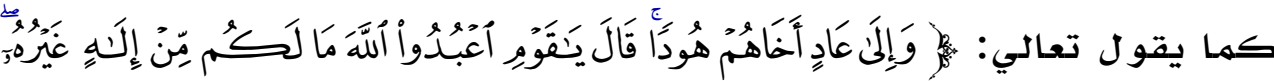

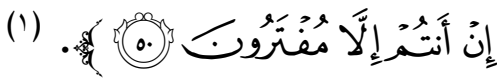

أما تأثير قيمة العالمية فهي تعني:- أن الإسلام رسالة يجب علي الأمـة أن تبلغها إلي العالم لإنقاذه من الضـلال و الشقاء. (r)، فلذلك كانت النظم

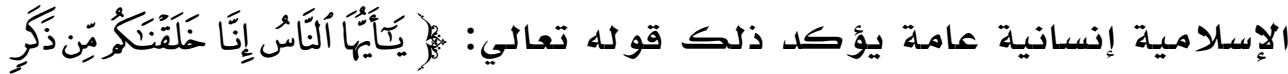

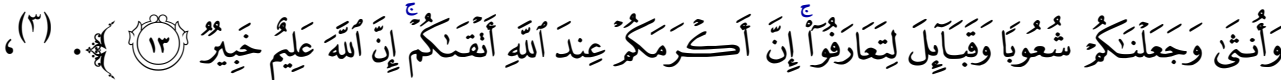
فالقر آن الكريهم يبين أن اصل الخلقة واحدة لا تفاضل بينهم في هذا الأصل، ويصرح بأن أتقاهم لله و أقربهم منه هو أكرمهم و أفضلههم قال

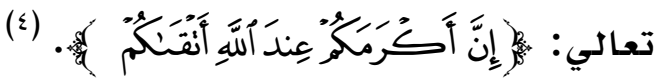

ثانياً: تأثير خصيصة التكامل والتناسق: إن خصائص الإسلام متتكاملة له تتركك أمـر أ مـن أمور الدنيا و الآخرة و لا فعلاً مـن أفعال الإنسان و لا تصر فاً من تصر فاته و لا إتجاها مـن إتجاهاته إلا أعطته حكمهـ الشرعي وو ضعه في ميز انه الحقيقي وجعلَت كلاً منهها مـرتبطاً بالعقيدة الإسلاميـة بر باط وثيق

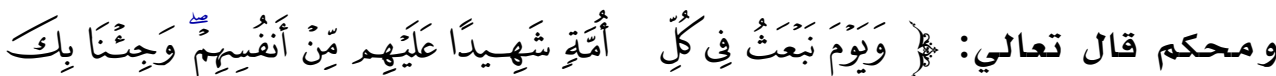

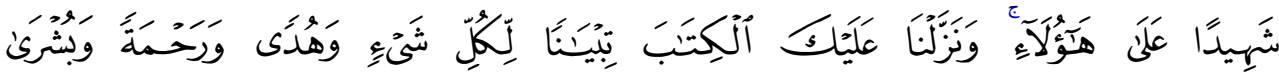

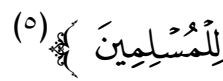

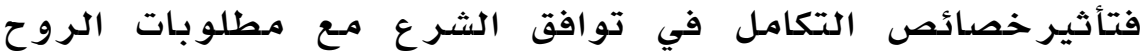
و الجسلد، فهن نعم الله على العبـاد أن أباح لهم الهأكل و الشرب، و الهلبس،

$$
\text { 0. (1) سورة هود الاية (1) }
$$

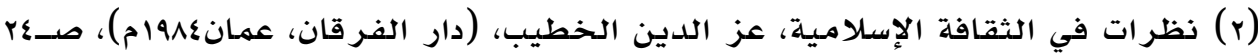

$$
\begin{aligned}
& \text { (r) سورة الحجر ات الآية: سالهرية }
\end{aligned}
$$

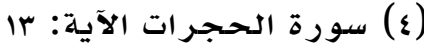

$$
\begin{aligned}
& \text { (0) سورة النحل الآية: } 19
\end{aligned}
$$

110 
و النكاح و العلاج فحقق للجسـد مطلوباته، وشرع العبادات التي تسهو بروح الإنسـان، ورغب سبحانه و تعإالى في الاهتمام بالروح لكونها تسهمو بالجسد و لكونها تبقى بعد فناء الأجساد، فهذا التكامل هو سهمة بارزة مـن هذه الخصسائص الثقافية الإسلاميـة، فهي تضهم جميع شئون الحياة، فلا يجوز فصل جزء مـن هذه النظهم و لا أَخْذ بعضها وترك الآخر، فمثلاً لا يجهوز القيام بأداء الصدلاة وترك الزكاة، ولا ينبغي للهسلهمة أن تخرج الشارع متبر جـة، فهذه الحقيقة تجعل الإنسان يجهـع بين جميـع جوانب الحياة . ثانثا: تأثير خصيمة الوسطية: الإسلام دين الوسط والاعتدال في عقيدته وشريعته وشعائره و نظمه، ففي قضية الألوهية تتوسط العقائد بين الهـالاحِدة الذين لايؤُمنون بالله تعالي وبين الذين يعلددون الآلهة حتي عبدوا البقر و الأغنام و الكواكب وغير ها، فخلافاً لذلك إن العقيدة الإسلاميـة تدعوا إلي إله و احد لاشريك لله وهو مالك الهلك وهو علي كل شيء قدير، و كذلك من و صفوا الله بصفات البشر وبين من سلبوا منه الصفات ونفوها عنـه، فالعقيدة الإسلامية أثبتت لله تعالي كل صفات الكمال ونزهته

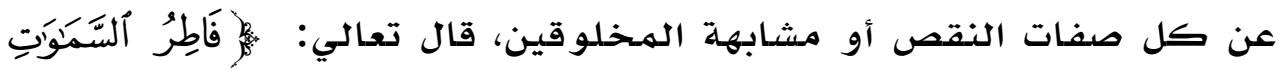

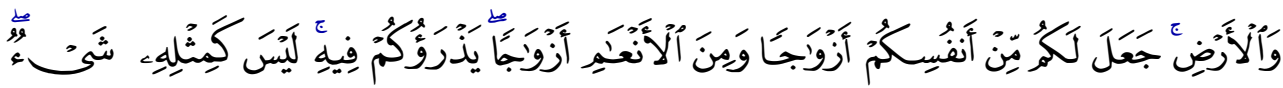

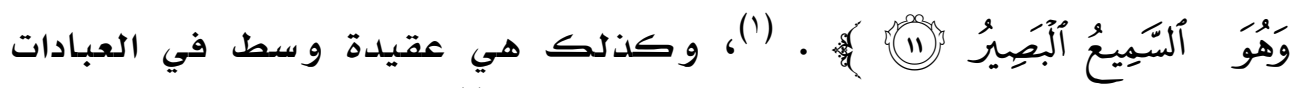

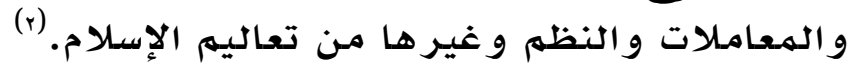

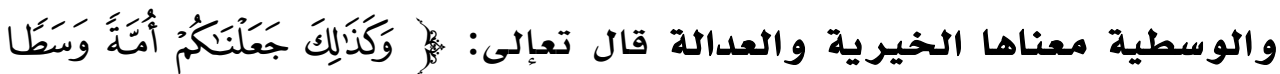

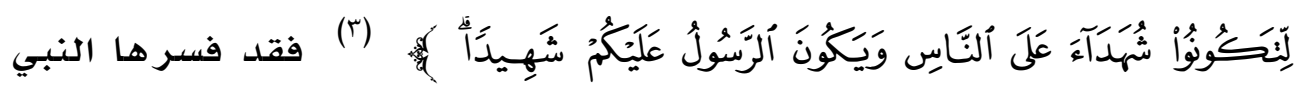
صلى الله عليه وسله في الحديث الصحيح بالعدالة حيث روى البخاري

$$
\text { (1) سورة الشوري الآية: }
$$

(r) دراسـات في الثقافة الإسلامية، أحمد محمدد أحمد جلي، الطبعة الأولي، (شركة

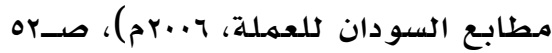

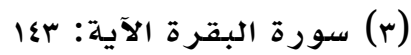


و الترمدي عن أبي سعيد [الخدري] رضي الله عنه قال: قال رسول الله -

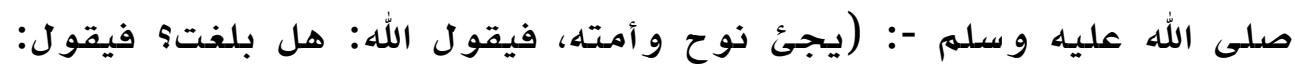

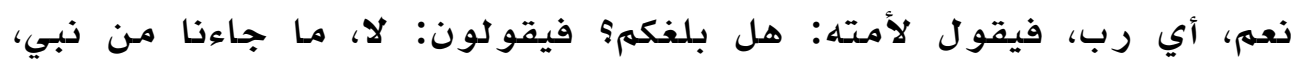

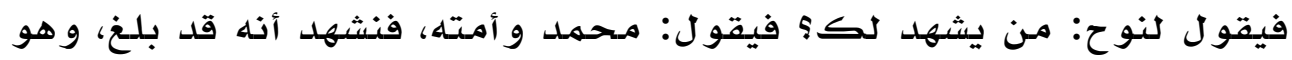

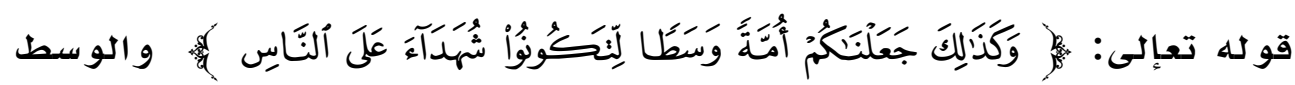

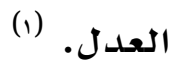

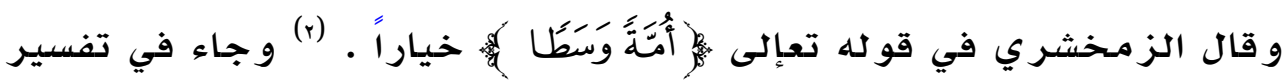

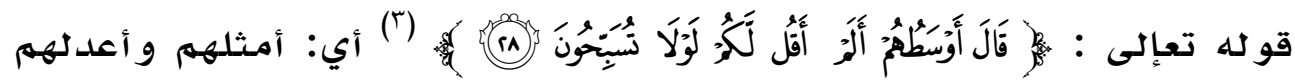

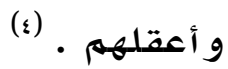
أما معنى العدالة عند الفقهاء بأنها: (انها مقصد الصدلاح في الدين

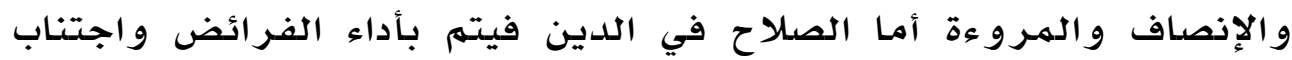

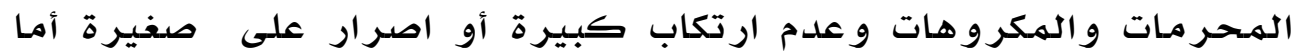

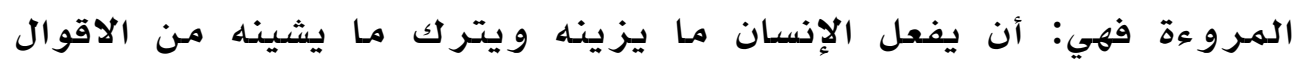

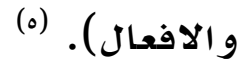
الاطلب الثالث: تأثير خصائص الثبات والمرونة، الإيجابية والواقعية، في تحقيق الأمن الثقافي:

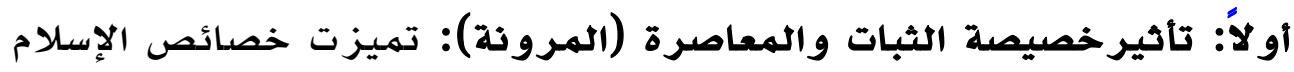

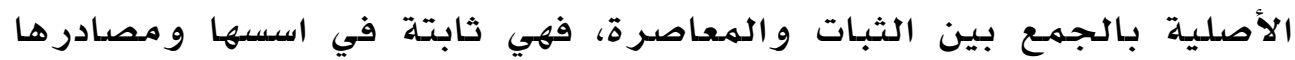

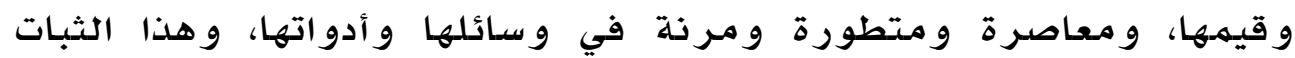

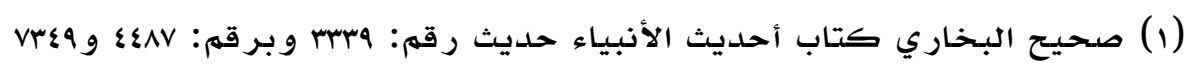

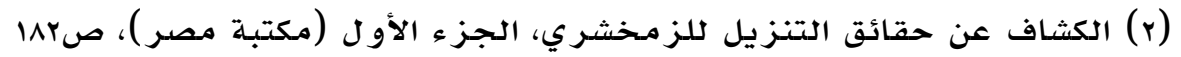

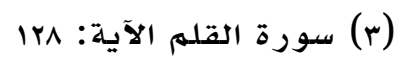

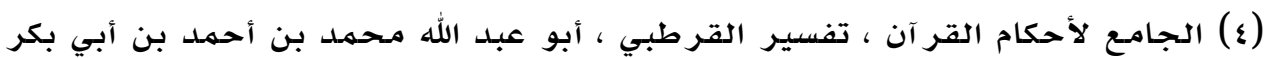

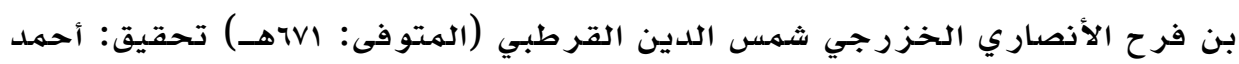

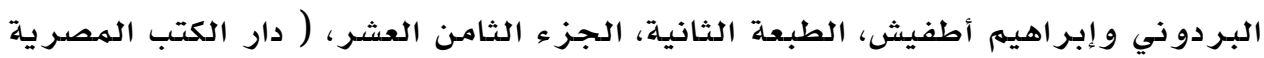

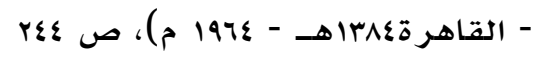

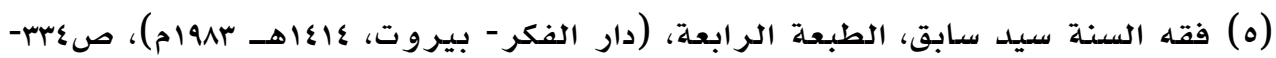


لايعني الجمود وقتل الإبداع أو التوقف عن الحركة؛ وإنما هو قمهة الحرركة والإبداع ولكن في إطار الحقائق والقواعد الإسلاميلة مـع ضمان هحة و اتزان هذه الحركة في سير ها إلي غاياتها دون تحيزز أو ضلالول. (1) جمعت الخصدائص في النظم الإسلاميـة، بين الثبات والهـرونة في تناسق مبدع، واضعة كلاً منهما في موضعـه الصحيح الثابت فيما يجب أن

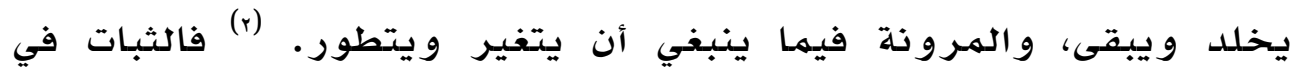
مقومـات التصور الإسـلامي وقيهـه هو الذي يضهن لنظام الحيـاة الإسـلامية

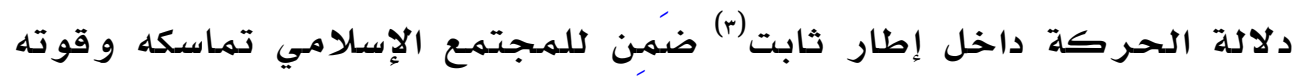
على مدى أكثر من الف وأربعهائهة عام رغم جميع الابتلاءات التي مـر بـه. لذا اتسعت لتشهل ما يتجدد مـن الأحداث و الهعامـلات الهختلفة، ورأينا تغيّر الفتوي واختلافها بسبب تغيّر الأزمنة والأمكنة والأحوال، و نستطيع أن نحدد مـجـال الثبات ومـجال التطور أو الهـرونة في الشريعة الإسلامية ورسالتها الخالدة فنقول: إن الثبات في الأصول و الكليات، و الهـرونة في الفروع والجزئيات، وكذلك الثبات علي الأهداف و الغايات و الهـروونة في الوسائل و الأسـاليب.

إن ثبات خصائص الإسلام تضبط حركة الإنسان وتقيد تصرفاته ضهـن إطار محلدد فلا يخرج مـن جادة الهدي ولا يحيد عن جادة الطريق

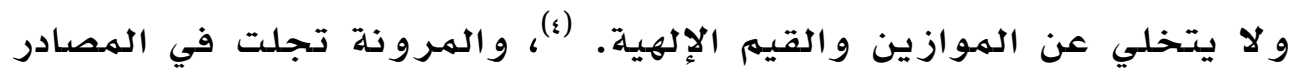
الاجتهادية التي اختلف فقهاء الأمهة في مدى الاحتجاج بها مـا بين مـوسِع

(1) نحو ثقافة إسلاميلة أصيلة، عمر سليمان الأثقر و آخرون، الطبعة السابعة، (مكتبـة

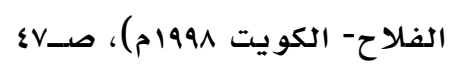

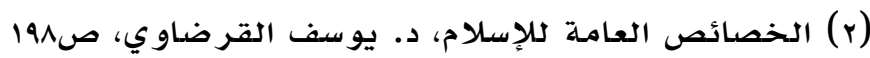

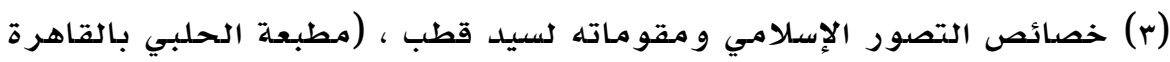



(ع) الوافي في الثقافة الإسلامية، مصلح بن عبدالحي النجار، (مكتبـة الرشد ناشرون، 
و مضيّق ومُقل ومكثر (1)، فإن مجال الاختيار فيها واسع وهي مروونة كافية لهواجهة ما يتو لد في حياة الناس من مواقف وحوادث وما تصير إليـ الأمور في المهجتمعات و هي مـها يحتاج إلى نظر وتأمل و استتبـاط، وقد قسهم ابن القيهم -رحهـه الله -الأحكام بناء” على ما سبق إلى قسهين: النوع الأول ما لا يتغير عن حاله بحسب الأزمنـة ول الأمكنة و لا إجتهاد الأثمهة، و الثاني: ما يتغير بتغير المصدلحة له زمانا ومكانا وحالا، كمقادير التعزير ات و أجناسها و صفاتها، فإن الشار ع ينوع فيها حسب الهصلـحة.

و خلاصدة القول إن الخصائص في النظم الإسلاميـة، تلتقي فيها قيهم الثبات و الهـرونة، كها تلتقي كل الهعاني الهتقابلة، التي يظن كثير من

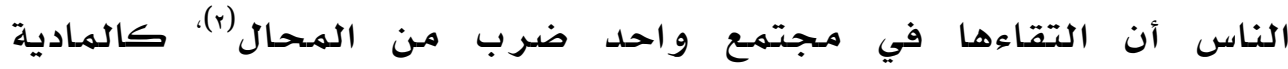
و الروو حيـة، و المثالية و الو اقعيلة.

ثانياً: تأثير خصيصة الإيجابية:- من دلالات خصائص الإسلام أنها إيجابيـة في كل جانب مـن جوانب الحياة، وهي تجعل الإنسان الهثقف يعيش في حركة فكرية و نفسية وجسدية بناءا بعيداً عن السلوك التخريبي الهدام رافضاً التحجر والجمود و لا ير ضي بالسلوك الانهزامسي الذي يتهرب من ون نشاطات الحياة وبعيد عن مواجهة الصعاب لأن النظم الإسلامية تبنى في الإنسـان السليهم الروح الإيجابية التي تؤهله للعطاء وتنهي فيه القدرة علي

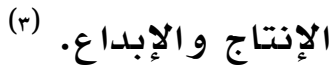

(1) إغاثة اللهفان من مصائد الشيطان، ابن القيه الجوزية، //.بr-اسب. بتصرف فيسير.

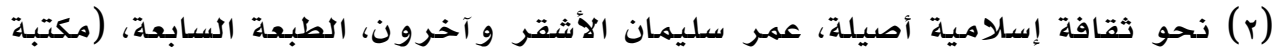

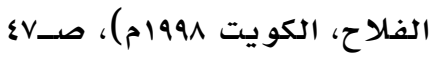

(r) الوافي في الثقافة الإسلامية، مصلـح بن عبدالحي النجار، مـرجـع سـابق ، صــهـ 
فهذه القيهم الإيجابية تعاملت مـع الإنسـان أنه مكلف ومتحمل لـلأمانة قال

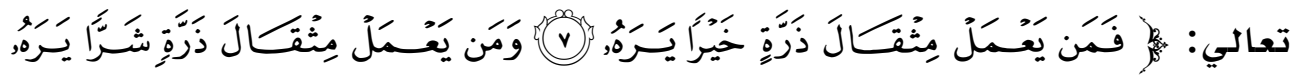
(1) $\cdot(1)$

ثالثاً: تأثير خصيصة الواقعية:- خصائص الإسلام ذات ثقافة و اقعية لأنها تر اعي قدرات الإنسان وتعترف بضعفه و أنه يخطئ ويصيب، وتعهل علي الارتقاء بـه من خلال دفعه للهمجاهدة والسعي نحو الأعمال الصالحات و التوبة من الهعاصي و تلدعو إلي الاقتداء بالأنبياء و الصالحين.

فير اد بخصائص الإسـلام، ودورها في تحقيق الأمـن الثقافي، مـر اعاة و اقع الكون من حيث وجوده الحقيقي، وواقع الحيـاة من حيث هي مرحلة حافلة بالخير و الشر، وواقع الإنسـان مـن حيث خلقته الهزدوجة فهو نفخة من روح الله في غلاف مـادي من طين. (r) فنسجد قيمـة الواقعية في النظم الإسلامية في جميع مجالات الإسـلام العقدية والتشريعية والأخلاقية، حقائق، ثابتة و ليست أفكاراً متخيلة في الأذهان تقوم علي الظن و الوهم، و إنها هي تقوم علي القر آن الكريهم والسنـة النبـويـة الشريفة. و ومن الهـلاحظ أن خصائص الإسـلام لها سهات وخصائص ووظيفة تختلف بها عن غيرها من الثقافات التي هي من وضع البشر، وهـ أبرزها: خصائص الربانية، و الإنسـانية و العالهية، والتكامل و التناسق، والوسطية، و الثبات و الهـرونة،

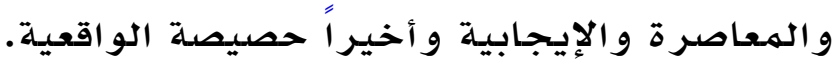

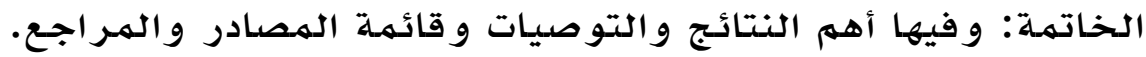

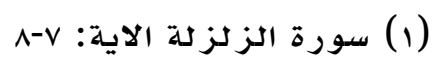

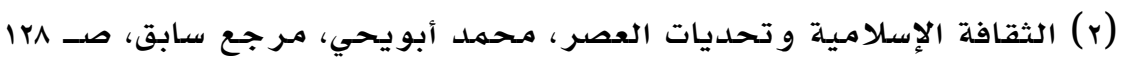


الخخاتمة:

ان سعي الإسلام بتشر يعاته و أحكامـه و مُثله وخصائصسه إلى تحقيق الأمن والأمـان في الأرض، ولا يتناقض هذا مـع حثثه على الزهد في الدنيا و الرغبـة عنها، فالأمن الثقافي لا يتم الا بتطبيق أحكام الشرع و تطبيقاته تسبقه النيـة، وهذه النيـة هي بساط الهؤمس إلى الآخرة، فنشر دين الإسلام في الأرض و العهل بهتضاه يفضي إلى تحقيق الأمـن بكل أذواعه و الفلاح في الآخرة، فينتفي التضاد بين الأمـرين.

أولاً: أهم النتائج:

ا. إن خصائص الإسـلام هي الأسس التي يبنس عليها الدين ويتهيز بها عن غيرهـ r. أسس و مصسادر التشريع في الكتاب والسنـة. r. وأن أهم مـاتهيزت بـه شريعة الإسلام أنها سعت لتحقيق مصاتح العبـاد في كل زمان عبر تشر يعات و أنها من قبل مشرِّع حكيهم. ع. التلازم بين الإيهان والأمـن في قول رسول الله صدلى الله عليه وسلهم:

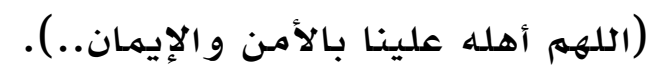
ه. كما أن تحقيق الأمن الثقافي يشبع حاجـات الإنسان الهعندوية و الثثافية.

7. في المجال الثقافي نجد أن الأمن مهم لحماية الأمـة مـن التيارات الثقافية لا لـيما الهدامـة منها. ثانياً: أهم التوهيات: ا- لابـ من رعاية الأمن الثقافي بـاستخدام جهميع الوسائط الهـهنة بهـا فيها المستحدمثة. ץ- كذلك الإهتمام بخصائص الإسلام، والكتابة حول الأمن وأهميته و أنه مـربوط بالأمـن الغذائي والإجتماعي. ب- يوصي الباحث بالكتابة عن كيفية حماية الثقافة الإسلامية الأصيلة من التيارات الهعاصرة، وأخيراً توضيح الربط الطي القوي بين 191 
الأمـن الغذائي و الثقافي، و السياسي، و الجغر افي، و غير ها.

ع- تحقيق الأمن الثقافي يحافظ على الهويـة الثقافية كلأمـة الإسـلاميـة. ه- ان خصائص الإسـلام تحافظ على الهاضي وتثري الحاضر

$$
\text { و المستتقبل. }
$$

ج- لذا فإن خصسائص الإسـلام ما هي تحقيق للأمس الثقافي الذي يشكل النسق الإجتهماعي، وهو نسقاً فر عيا متهـيزأ و مستقلاً، لكنهه يتفاعل مع بقية الأنساق الفرعية الأخرى ويتطور معها وبها، ويقوم الأمن الثقافي بتكوين جملـة الطرائق والمعايير التي تحكم رؤية الإنسـان للواقع؛ لذلك فإن الثقافة هي مسجموع القيم و القواعد والأعراف و التقاليد والخطط التي تبدع وتنظم الدلالات العقلية والروحية

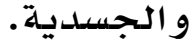




\section{ثالثاً: قائمة المصادر والمراجع:}

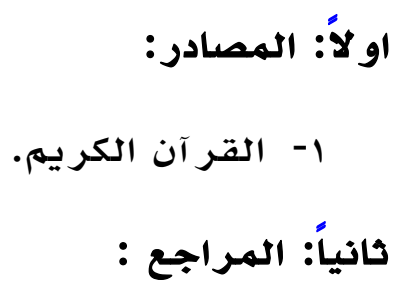

ץ- الأحكام السلطانية والولايات الدينية، علي بن محمد حبيب البصري

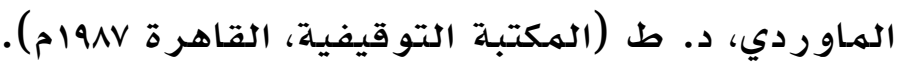

ب- الإحكام في أصدول الأحكام للآمدي :الجزء الأو ل. ع- الأخلاق والنظهم ،أ • د • جعفر شيخ إدريس، مـلـة البيان، العدد

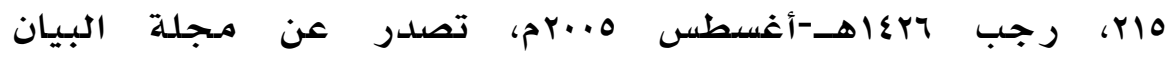

$$
\text { 0- إرشـاد الفحول. الإسلام. }
$$

צ- أساس البلاغة، للزمهخري مـادة ثقف، (دار صسادر، بيروت الطبعة

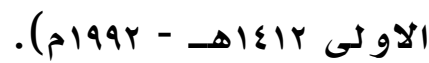

$$
\begin{aligned}
& \text { - V اصطلاحسات الصوفية ،لابن عربى. }
\end{aligned}
$$

^- أصول التربية الإسلامية بين الأصالة والمعاصرة، صبسحي حمدان

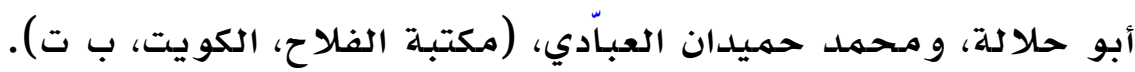
ه- أصول التربية الإسـالامية و أساليبها في البيت و الهمدرسة و الهـجتهـع،

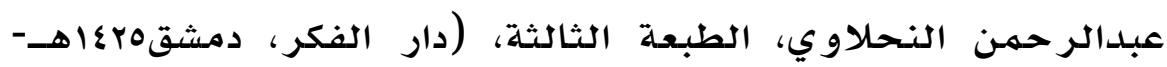

$$
\text { . (مr... }
$$

• ا- أصول التربية الإسـلاميلة و أسـاليبها في البيت و الهمدرسه و الهمجتهـع،

$$
\text { عبدالر حمن النحملاووي. }
$$

ا - أصول التربية الإسلاميـة، مححمد عبدالسـلام العجمهي.

rا- إغاثة اللهفان مـن مصائد الشيطان، ابن القيهم الجوزية. سا-الأمن الثقافي العربي والتحديات و آفاق المستقبل، محمهود مححمد النحيري، د. ط (دار النشر التربوي للدراسـات الأمنية و التدريب،

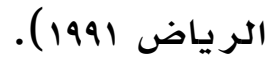


عا-الأمن والمخابرات نظرية إسلامية، علي نهيري، الطبعة الأولى،

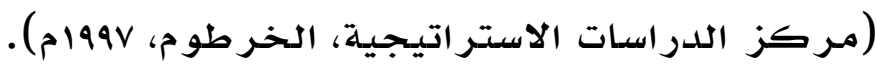

10- بحوث في التربية الإسـلامية، سعيد إسهـاعيل علي.

7ا-التربية مفاهيهم وحلدود و مضامين، في مدخل التربية، علي أسعد و طفة .

Vا-التربية وطرق التدريس، عبدالرحمن النحلاوي، و آخرون،الطبعة

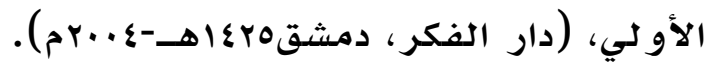

1ا-تفسير القر آن الكريهم لالإبن كثير إسهماعيل بن كثير القرشي الدمشقي، بتحقيق الألباني، الجزء الر ابع، الطبعة الأو لى، (دار البيان

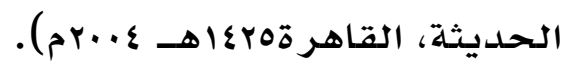

19-تهذيب اللغة، أبو منصدور الأزهري، تحقيق: عبدالسلام هارون،

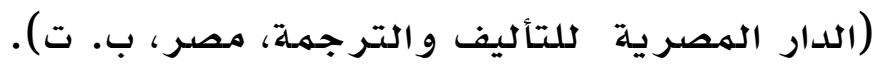

•ץ- تيسير التحرير، مححمد أمين، الهعروف بأمير بـادشاه، الجزء الثالث،

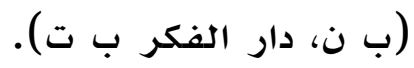

اب- الثقافة الإسلامية و تحديات العصر ، محمد أبويحي). ץץ- خصائص التصور الإسـلامي و مقوماته لسيد قطب، (مطبعة الحلبي

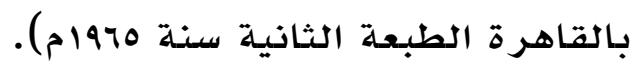
بr- خصائص التمكين وقيمـه في الإسـالام، د. سـاميلة توفيق صالح عثمان، مجلة كلية الدعوة والإعلام، العدد الثاني لسنـة صفر بسعاهـعابrrم، تصدر عن كلية الدعوة والإعلام، بجامعة القر آن الكريها

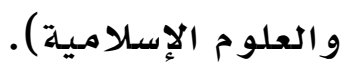

ع - الخصائص العامـة لإِسـلام، د. يو سف القر ضاوي. هץ-دراسـات في الثقافة الإسـلاميلة، أحمد محمد أحمد جلي، الطبعة

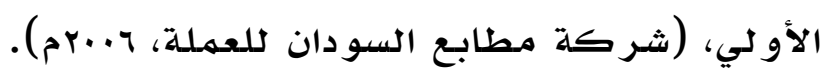

جץ-دور و سـائل الإتصال الجماهيري في تعزيز الأهـن، أ. د. محمد

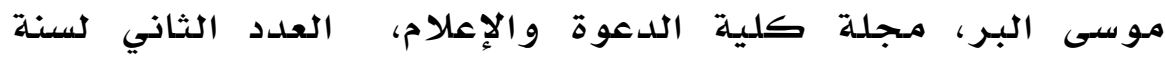

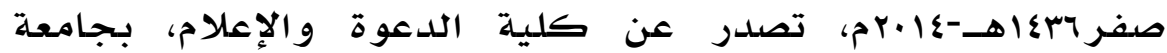
القر آن الكريهم والعلوم الإسلاميـة. 
Y - الر سـالة القشيرية.

^ץ- سنـن أبي داوود، أبو داوود سليهان ابن الأشعث بن إسحاق بن بشير بن شداد بن عهرو الأزدي الستجستاني المتوفي، (هVoهـ)، تحقيق: محمد مهحي الدين عبدالحهيد، كتاب الآداب، باب في العصبية، الجزءء الر ابع،(الهكتبـة العصر يـة صيدا د د ت) .

$$
\text { . }
$$

• ب- صحيح البخاري، مهمدل بن اسهـاعيل البـخاري، الطبعة الأولى، الجزء

$$
\text { الثالث عشر، (دار طوق الننجاة، بيروت-بوعاهـ). }
$$

اس- صحيح مسلم بن الحجاج النيسابوري، الجزء الثاني، د. ط (دار إحياء التر اث العر بي، د. د. ت) .

ץم-علهم الدلالة، احمد مختار عمـر، الطبعة السـادسـة، (دار عاله الكتب،

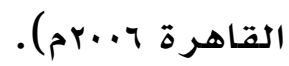

سم- علهم النفس الدعوي، مححمد زين الهادي العرمابي، الطبعة الرابعة،

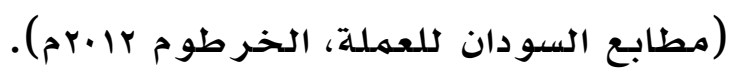

عس- في فقه السنن والحضسارات كيف نتجاوز سلبيات المـرحلة و نعاود البناء ؟، د. سليهان عبد الدايهم الخطيب، مـجلة البيان، العدد عץا،

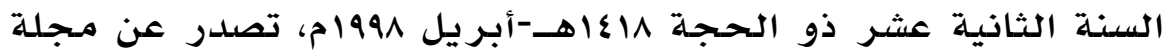

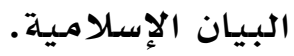

هب- القاموس الهحيط، محهد بن يعقوب الفيروز آبادي. بس-القيهم الإسـالاميـة، على خليل ابو العنين. Vr-القيم التربوية في السنن النبوية (رسالة دكتوراه)، سمية

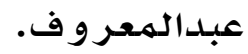

^ץ- كشف الأسرار كلنسفي مع نور الأنوار كلمالاجيون الجزء الأول. هب- كنز العهال في سنن الأقوال والأفعال، علاء الدين علي المتقي بن حسـام الدين الهندي، الجزءء السـابع، د. ط. (مؤسسة الرسالة، بيروت

$$
\text { - (5) } 1911
$$

•ع- لسان العرب، ابن منظور أبو الفضل جهال الدين،الجزء الأول (دار إحياء التر اث العربي للطباعة و النشر و التوزيع، بيروتهوتهوابم). 
اع- مـختار الصحاح محمدل بن ابي بكربن عبدالقادرالرازي،الطبعة الثالثة

$$
\text { (دار الهعار ف،مصر بدون تار ينخ) . }
$$

بع-مهتار الصحاح، محمد بن أبي بكر بن عبدالقادر الرازي، تحقيق:

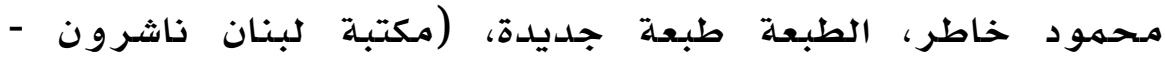

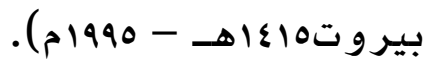

بع- المداخل إلى القيهم الإسـلاميـة، جـابر قهيـحة.

ع - مشكل الآثار للطحاوي.

هـ-الهصباح الهنير في غريب الشرح الكبير للر افعي، أحمد بن محمد بن علي الهقري الفيومس، (بيروت، الهكتبـة العلمية د.ت). جع- معالم الثقافة الإسـلامية، عبدالكريهم عثمان، بدون طبعة. Vـ-الهعجم الإسلامي، إعداد أشرف طه أبوالدهب، (دار الشروق -

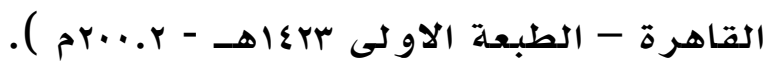

^ع- المعجم الوجيز، مـجمع اللغو العربية، د. ط، (مجهمع اللغة العربية،

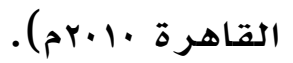

9؟-الهعجم الوسيط مجهم اللغهة العربية، إبراهيم مصطفي و آخرون،

$$
\text { طب، (تر كيا، الهكتبـة الإسـلاميـة ب ت ) ). }
$$

•0- معجهم مقاييس اللغة لأبي الحسن أحمد بن فارس بن زكريا، الجزء الثاني، (دار الجليل بيروت - ذبنان - الطبعة الأو لى العاهـ) . اه- الهفردات في غريب القر آن، الر اغب الأصفهاني أبو القاسهم الحسين بن محمدل، تحقيق: مححمد سيد كيلاني، د. ط (شركة و ومكتبـة

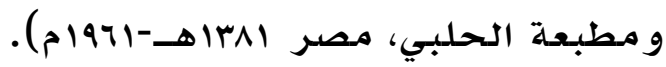
به- الهفهوم الأمني في الإسلام، علي بن فائز الجحني، مهلمة الأمن

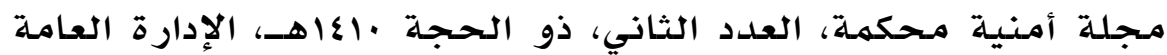

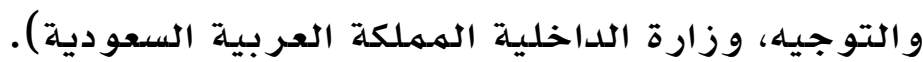
به- الهقاصد العامـة للشريعة الإسلاميلة، العاله، يوسف حامد، (منشوررات

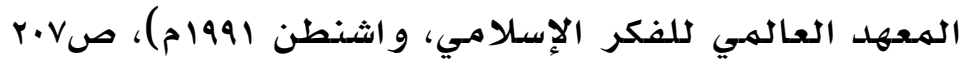
عه- الهنظو مـة القيهيـة الإسـلامية، مـروان إبر اهيهم القسي. هـ- نحو ثقافة إسلامية أصيلة، عمر سليهان الأثقر و آخرون، الطبعة 
مجلة معام الدعوة الإسلامية المحكمة- العدد (الثاني عشر)- ربيع الثاني rعاهـ / ديسمبر •r.r

$$
\text { السابعة، (مكتبة الفلاح، الكويت في الكوام). }
$$

به-نظرات في الثقافة الإسلامية، عز الدين الخطيب، (دار الفرقات الدان،

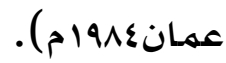

-OV الوافي في الثقافة الإسلامية، مصلح بن عبدالحي النجار، (مكتبة

الرشد ناشرون، الهملكة العربية السعودية، الرياض د-ت).

ه- Sahih Muslim - The book on mosques and places of prayer, chapter on the desirability of remembrance after prayer and its description, Hadith No. 4ז. 